Illinois State University

ISU ReD: Research and eData

Theses and Dissertations

7-13-2020

\title{
Collaboration In The Technical Communication Classroom: Negotiating Team Contracts In A Pwi
}

Alyssa Herman

Illinois State University, alyssa.j.herman@gmail.com

Follow this and additional works at: https://ir.library.illinoisstate.edu/etd

Part of the Educational Methods Commons, Other Communication Commons, and the Rhetoric Commons

\section{Recommended Citation}

Herman, Alyssa, "Collaboration In The Technical Communication Classroom: Negotiating Team Contracts In A Pwi" (2020). Theses and Dissertations. 1290.

https://ir.library.illinoisstate.edu/etd/1290

This Thesis is brought to you for free and open access by ISU ReD: Research and eData. It has been accepted for inclusion in Theses and Dissertations by an authorized administrator of ISU ReD: Research and eData. For more information, please contact ISUReD@ilstu.edu. 


\title{
COLLABORATION IN THE TECHNICAL COMMUNICATION CLASSROOM: NEGOTIATING TEAM CONTRACTS IN A PWI
}

\begin{abstract}
ALYSSA HERMAN
74 Pages

As TPC teacher-scholars, we must acknowledge the overwhelming Whiteness of our field and the racism, ableism, and sexism inherent in our institutions. We must actively work toward inclusivity and socially just collaborations in our classrooms by encouraging dominant-identified students to confront their privileges and implicit biases in order to better engage with historically marginalized students. With that said, this thesis examines how teacher-scholars might take up a cultural-rhetorical approach to teaching TPC and how we might negotiate team contracts in PWIs. Firmly situated within the social justice turn, Herman draws from both feminist disability theory and critical race theory to build a Feminist DisCrit methodological framework. Herman then presents her pilot study on student collaboration, which examines the ways White male and non-disabled normalcies permeate the TPC classroom and impact student interactions. Extending this framework and data, Herman provides an infrastructure for TPC teacher-scholars to build team contract handouts and provides a situated example of a team contract curricular approach to encourage more socially just collaborations between dominant-identified and historically marginalized students in the classroom.
\end{abstract}

KEYWORDS: cultural rhetorics, normalcy, social justice pedagogies, student collaboration, team contracts, technical and professional communication 
COLLABORATION IN THE TECHNICAL COMMUNICATION CLASSROOM:

NEGOTIATING TEAM CONTRACTS IN A PWI

ALYSSA HERMAN

A Thesis Submitted in Partial

Fulfillment of the Requirements

for the Degree of

MASTER OF ARTS

Department of English

ILLINOIS STATE UNIVERSITY

2020 
(C) 2020 Alyssa Herman 
COLLABORATION IN THE TECHNICAL COMMUNICATION CLASSROOM:

NEGOTIATING TEAM CONTRACTS IN A PWI

ALYSSA HERMAN

COMMITTEE MEMBERS:

Julie Jung, Chair

Barbi Smyser-Fauble 


\section{ACKNOWLEDGMENTS}

First, I would like to thank my two committee members for working with me so closely over the last year. Dr. Jung's overall guidance and cultural rhetorics expertise paired with Dr. Smyser-Fauble's technical communication expertise shaped this thesis into what it is now. I truly appreciate their consistently insightful perspectives and the labor they put into this thesis. In addition to Dr. Jung and Dr. Smyser-Fauble, I thank the mentors who have challenged my thinking and helped me grow over the last few years: Dr. Angela Haas, Dr. Erika Sparby, Dr. Bob Broad, Dr. Maria Novotny, and the many others I cannot begin to list. I thank my significant other, my ISU family, and my biological family for their unending love and support. Most importantly, I thank the scholars and activists who have come before me, who continue to model the physical, emotional, and intellectual labor necessary to redress inequities and further the social justice turn.

A. J. H. 


\section{CONTENTS}

Page

ACKNOWLEDGMENTS

TABLES

FIGURES $\quad$ v

CHAPTER I: ENGAGING IN CONVERSATIONS ABOUT RACE,

DISABILITY, AND GENDER: AN INTRODUCTION 1

$\begin{array}{ll}\text { Scholarly Turns in TPC } & 3\end{array}$

The Humanistic and Sociocultural Turns 3

$\begin{array}{ll}\text { The Social Justice Turn } & 6\end{array}$

$\begin{array}{ll}\text { The Need for Social Justice Heuristics and Frameworks } & 7\end{array}$

Positionality, Privilege, and Power: The 3P's Model 8

Theoretical and Methodological Framework 11

$\begin{array}{ll}\text { Feminist Disability Theory } & 11\end{array}$

$\begin{array}{ll}\text { Critical Race Theory } & 13\end{array}$

Tenets of Feminist DisCrit 14

$\begin{array}{ll}\text { Positionality, Privilege, and Power as a Researcher } & 15\end{array}$

$\begin{array}{ll}\text { Chapter Overview } & 17\end{array}$

CHAPTER II: INVESTIGATING COLLABORATIVE CONFLICT AND

THE AVOIDANCE OF CONFLICT IN THE TPC CLASSROOM 19

$\begin{array}{ll}\text { Collaboration in the TPC Classroom } & 20\end{array}$

$\begin{array}{ll}\text { Challenges and Student Conflict in Classroom Settings } & 21\end{array}$

Pilot Study on Student Collaboration in the TPC Classroom 24 
$\begin{array}{ll}\text { Participants } & 25\end{array}$

$\begin{array}{ll}\text { Coding and Data Analysis } & 26\end{array}$

Lack of Control and Comfort in Collaborative Work $\quad 27$

Collaborative Writing as Divided and Individual 32

Student Solutions to Collaborative Complications 34

CHAPTER III: TEAM CONTRACTS AS A METHOD FOR SOCIALLY

$\begin{array}{ll}\text { JUST STUDENT COLLABORATIONS } & 37\end{array}$

Methods for Encouraging Student Collaboration 38

$\begin{array}{ll}\text { Grading Contracts } & 39\end{array}$

$\begin{array}{ll}\text { Team Contracts } & 40\end{array}$

General Infrastructure for Building a Team Contract 41

Situated Example of a Team Contract Curricular Approach 46

Limitations and Implications for Future Research $\quad 54$

$\begin{array}{ll}\text { Conclusion } & 57\end{array}$

$\begin{array}{lc}\text { REFERENCES } & 63\end{array}$

APPENDIX A: SURVEY QUESTIONS $\quad 70$

APPENDIX B: PARTICIPANT DEMOGRAPHICS 72

APPENDIX C: CLIENT PROJECT ASSIGNMENT SHEET 74 


\section{TABLES}

Table

Page

1. Infrastructure for TPC Teacher-Scholars to Plan Team Contract 43 Handouts 


\section{FIGURES}

Figure $\quad$ Page

1. Team Contract Preparation Handout 49

2. Client Project Team Contract Handout 50 


\section{CHAPTER I}

ENGAGING IN CONVERSATIONS ABOUT RACE, DISABILITY, AND GENDER:

\section{AN INTRODUCTION}

Ensuring that our research practices and pedagogies are inclusive has become an important and necessary task for technical and professional communication (TPC) teacher-scholars. As the TPC field is grappling with issues of systemic racism and the structural opportunities of Whiteness ${ }^{1}$, we are also trying to examine the ways that cultural-rhetorical research practices and pedagogies might encourage inclusivity in our research, in our classrooms, in the discipline, and in our institutions as a whole. We have reached a point where we can no longer ignore the overwhelming Whiteness of our field and institutions, and we must address the ways that institutionalized racism has silenced BIPOC (Black, Indigenous, and People of Color) teacher-scholars and students. The question we must ask, then, is: How can we, as TPC teacher-scholars, actively promote inclusive practices in a field and in institutions that continually (re)produce and normalize racist ideas and policies?

With these specific issues in mind, this thesis examines how instructors might take up a cultural-rhetorical approach to teaching TPC and how we might negotiate team contracts ${ }^{2}$ in a predominantly White institution (PWI). I would like to acknowledge upfront that as a graduate student, I have only taught first-year composition courses here at Illinois State University (ISU), and I have not had the

\footnotetext{
${ }_{1}^{1}$ Throughout this thesis, I have intentionally made the decision to capitalize "White" when referring to the racial category. In my mind, to not capitalize "White" is to not recognize White as racialized, which risks reproducing Whiteness as the default.

${ }^{2}$ Here, I am referring to team contracts in the pedagogical sense. The "team" constitutes a group of students who are about to engage in a collaborative endeavor/project, and the "contract" is a means through which the group of students may negotiate individual goals, differences in literacies and access, individual responsibilities, leadership roles, etc. I address team contracts more explicitly in chapter three.
} 
opportunity to teach a TPC course yet. However, I am an invested and thoughtful practitioner of TPC, and I would like to establish myself as a future teacher-scholar of TPC and cultural rhetorics. This thesis is the preparatory work that needs to be done before I can implement a TPC course focused on embodied, inclusive, and socially just student collaborations.

My main research question for this thesis is: As TPC teacher-scholars, how do we negotiate team contracts in TPC courses in a PWI? This is my primary research question because there is a lack of research on team contracts and how team contracts may impact students who are historically marginalized at PWIs. To answer this specific research question, I must first consider what methodologies for teaching collaboration in TPC would encourage dominant-identified students to challenge their privileges and implicit biases and learn to engage with students from historically marginalized groups. For this reason, I have divided this chapter into four parts. In the first portion, I review scholarly turns in the TPC field, including the humanistic turn, the sociocultural turn, and the social justice turn. Reviewing these scholarly turns is necessary to explain why I take up a methodology firmly situated within the social justice turn. In the second portion, I establish the need for social justice heuristics and frameworks for teaching TPC and review one recent heuristic created by Jones, Moore, and Walton (2016) to employ a social justice approach: the $3 \mathrm{P}$ 's model. Reviewing the $3 \mathrm{P}$ 's model allows me to consider the ways that positionality and privilege relate to oppressive power structures and how teacher-scholars and students might learn to acknowledge their own positionality, privilege, and power. In the third portion, I engage with two major cultural-rhetorical theories: feminist disability theory and critical race theory. Drawing from these theories, I build a methodological framework, which I refer to as a Feminist 
DisCrit (FDC) approach to teaching collaboration in TPC. While this kind of approach has been used in other disciplinary areas, it has yet to be explicitly utilized in TPC research and pedagogical frameworks (Annamma, Ferri, \& Connor, 2018; Banks, 2018; Weiss, 2015). In the final portion, I give an overview of the chapters that follow.

\section{Scholarly Turns in TPC}

Before I can situate myself within contemporary TPC, it is important to note scholarly turns that have taken place in the field in the last forty years. Walton, Moore, and Jones (2019) define a scholarly turn as

a shift in emphasis and perspective. A turn comprises not only a wave of scholarship engaging with a particular concept, theory, or topic but also a more substantial shift, a transformation in thinking and meaning making. Marking a scholarly turn, a growing body of scholarship represents a fundamental and widespread shift in what the field is about, what it does, what it is for. (p. 6)

It is important to trace scholarly turns, as they constitute a field's identity and consequently inform our shared beliefs, values, research, pedagogies, and practices. For this reason, I will highlight three scholarly turns in TPC: (1) the humanistic turn, (2) the sociocultural turn, and (3) the social justice turn. While origins are difficult to mark and not every scholar of TPC agrees with or welcomes these scholarly turns, these bodies of scholarship have introduced important conversations that have affected the field of TPC as a whole.

\section{The Humanistic and Sociocultural Turns}

Jones et al. (2016) mark the beginning of the humanistic turn with Miller's (1979) article on "A Humanistic Rationale for Technical Writing." Miller (1979) refutes the idea that "science and rhetoric are mutually exclusive" and that technical writing is totally 
unbiased and unemotional (p. 611). Essentially, she believes this positivist view is outdated, and we are not just teaching TPC students a set of skills. Rather, Miller (1979) argues that we can teach TPC "not as a set of techniques for accommodating slippery words to intractable things, but as an understanding of how to belong to a community. To write, to engage in any communication, is to participate in a community" (p. 617). Miller (1979) calls for a turn away from the long nineteenth century version of rhetoric in TPC-where we aimed for total clarity and "objective" Truth in technical writing. Instead, she emphasizes the connection between language and communities and argues that humans-individually and collectively-cannot be separated from language and the study of rhetoric.

Cox (2019) suggests that Miller's humanistic approach to teaching TPC eventually led to the social turn and the cultural turn, separating the sociocultural turn into two distinct parts (p. 290). He marks the beginning of the social turn with Blyler and Thralls' (1993) collection, Professional Communication: The Social Perspective. Similar to Miller (1979), Blyler and Thralls (1993) reject positivism and stress the way local communities or social groups impact language and communication. However, the social turn can be distinguished from the humanistic turn, as TPC scholars associated with the social turn highlight "the centrality of socially mediated meaning" (Blyler \& Thralls, 1993, p. 4). Blyler and Thralls (1993) explain the social turn, or the social perspective, as follows:

Because there is no immediate knowledge of reality and because both knowledge and discourse are bound up with specific social groups, communications are invested with meaning only through the interactions of writers and readers in 
those groups. In short, socially mediated meaning-or, to use an alternate term, interpretation-is central to the social perspective. (p. 4)

In this way, Blyler and Thralls (1993) mark the beginning of a movement where TPC teacher-scholars attempt to analyze communication and audience reception within its larger social context and the ways that meaning is negotiated between the author and their audience.

Additionally, Cox (2019) considers Porter, Sullivan, Blythe, Grabill, and Miles' (2000) article, "Institutional Critique: A Rhetorical Methodology for Change," to be the beginning of the cultural turn in TPC. Porter et al. (2000) call for a turn in the fields of rhetoric and composition and TPC by asking teacher-scholars to engage in both institutional and disciplinary rhetorical critique. They emphasize the danger in equating “'institution' with 'discipline” and instead understand them in relation to each other, as "institutional change requires attention to the material and spatial conditions of disciplinary practices inside a particular institution" (Porter et al., 2000, pp. 618-620). Essentially, Porter et al. (2000) argue that institutional change cannot occur unless we examine "micro practices within the macro structures of an entire industry, which over time (and with the cooperation of others) can produce rhetorical and material change" (p. 627). Porter et al. (2000) make an important move as they begin to consider how institutions exert power over, limit access to, and further marginalize scholars and students. They argue that teacher-scholars need to be participating in institutional and disciplinary rhetorical critique in order to change the culture of the institutions they operate in. Ultimately, the sociocultural turn as a whole addressed "questions of power, authorship, and ethics" while also considering "our field's complicity in oppression" and marginalization (Jones et al., 2016, p. 3). 


\section{The Social Justice Turn}

The ethical questions raised in the humanistic and sociocultural turns made way for the social justice turn, where TPC teacher-scholars moved "from mere ethics, which often exist in an individual's character or behavior, to a social justice stance, which tends to be more collective and action oriented" (Jones et al., 2016, p.1). Jones et al. (2016) credit Rude's (2009) article on "Mapping the Research Questions in Technical Communication" as the beginning of the social justice turn. Rude (2009) separates research questions in TPC into four major categories, one category being "social change" (p. 176). Rude (2009) notes that TPC teacher-scholars concerned with "social change" generally consider the following research question: "How do texts function as agents of knowledge making, action, and change?” (p. 176). This "social change" approach began a movement in TPC where teacher-scholars considered the ways we might diversify the field in order to diminish the marginalization of underrepresented groups.

However, diminishing marginalization through diversity is no longer enough. Walton et al. (2019) note an important difference between diversity and inclusion: "We see diversity as a precursor to inclusion: Necessary but insufficient. Diversity brings a wide range of people to the table. But all too often, organizations and institutions remain unchanged by the addition of seats" (p. 8). Because "the isms" (racism, ableism, sexism, heterosexism, classism, etc.) are systemic, diversity is not enough. We have reached a point in the social justice turn where TPC teacher-scholars are calling for action through inclusivity in order to change the culture of institutions. Jones et al. (2016) define inclusivity as "efforts to forward a more expansive vision of TPC, one that intentionally seeks marginalized perspectives, privileges these perspectives, and promotes them through action" (p. 3). In this way, a social justice approach furthers 
diversity by actively working toward inclusion. In addition, a social justice approach refuses "to ignore or smooth over injustices in the name of moving forward" and “involves redressing inequities and acknowledging harm" (Jones et al., 2016, p. 9).

Employing a social justice approach means that we must make two essential moves: (1) We must acknowledge the damage the TPC field has done in being complicit in the oppression and marginalization of underrepresented groups; and (2) Those of us who are in privileged positions must actively listen to historically marginalized teacherscholars and students, privilege their experiential knowledges, and act on these knowledges in our research and pedagogies to promote disciplinary and institutional change.

\section{The Need for Social Justice Heuristics and Frameworks}

Just in case you think we live in a post-racial society, racism no longer exists in our institutions, or the culture of our institutions doesn't need to be changed, I'd like to pause briefly and offer you one example of many. In October of 2019, \#AntiBlackISU began trending on Twitter in response to a Black Homecoming Committee event being cancelled. The Black Homecoming Committee released the following statement on Twitter:

Our reservation got cancelled on Tuesday because of a last minute volleyball practice. The worst part is it felt like the cancellation was intentional. We are now unable to use other spaces because we're trying to book venues too close to homecoming. At this point, we have no chance to rebound. Besides the venue issues, we also run into a lot of problems when it comes to funding. We're not given the same funding that other predominantly [W]hite organizations receive because we don't cater to the majority but the issue is the majority doesn't cater 
to us. With that being said, ISU does not properly appeal to [B]lack students on campus. They recruit us to claim diversity but while we're here they do nothing for us. We have to create our own experiences as students that the university doesn't. (Black Homecoming Committee, 2019, Oct. 4)

The Black Homecoming Committee released more information on Twitter but were forced to delete most of their tweets. 3 Using \#AntiBlackISU, Black students began sharing their experiences on Twitter, including the many racist acts and microaggressions they've personally experienced with campus housing, the ISU police department, the dining center, in classrooms, and more. They also raised concerns about the lack of resources on campus, as many BIPOC students feel they are being recruited to raise diversity statistics but then not supported once they're here. I'm sharing this story to show that institutional racism exists, it's happening, and it's not unique to ISU. BIPOC students at universities across the U.S. are feeling commodified, unsupported, unwanted, and unsafe. Even events that seemingly take place outside of classrooms can severely impact classroom experiences, assumptions about BIPOC scholars and students, and collaborations in general. This is why it's so important to create social justice heuristics and frameworks that we can employ to actively work toward anti-racism in our classrooms. Our students need to feel valued, and they need to feel safe.

\section{Positionality, Privilege, and Power: The 3P's Model}

One heuristic set forth by Jones et al. (2016) to employ a social justice approach is the 3 P's model, which requires teacher-scholars to acknowledge positionality,

\footnotetext{
3 If you'd like to read the Black Homecoming Committee's deleted tweets, they can be found here in a Google Doc they created: https://twitter.com/BHC ISU/status/1183102352187895808.
} 
privilege, and power in their research and pedagogies. Because this model offers a social justice methodological approach in TPC that I seek to build upon, I review it here in detail before I discuss the theories that inform my methodology. As Walton et al. (2019) note, positionality is the idea "that aspects of identity (such as race, gender, nationality, religion, etc.) are complex and dynamic" (p. 65). In other words, one's positionality or identity is never stable, as it is highly contextual and depends on the rhetorical situation. Walton et al. (2019) argue:

Being attuned to positionality means recognizing that what it means to be one of the things you are-say "professor"-is affected by other aspects of your identity such as your race, gender, age, nationality, and other factors. And for those who do not fit the normative myth of a particular identity, the fit (or lack thereof) can cause strain. (p. 68)

Positionality, then, is a tool that allows us to consider the complexity of our intersectional identities in relation to the intersectional identities of others.

When I use the term "intersectional," I am specifically drawing from Crenshaw (1991) and Collins and Bilge (2016), who argue that our various identities can never be analyzed as separate categories. Rather, our identities compound, and oppression functions very differently for those who are multiply marginalized. Walton et al. (2019) give the following example: "if we are to understand the ways that oppression functions in the life of, say, a Black woman, we must consider the various oppressive structures that she lives with; the same is true for a transgender man with a low socioeconomic status" (p. 12). This example illustrates that while a Black woman and a transgender man are both oppressed, they are not "equally" oppressed. They are dealing with very different oppressive structures due to their unique positionalities. Once we recognize the 
intersectional nature of our positionalities, then we can begin to consider how privilege comes into play.

Privilege-or lack thereof-is a direct result of our positionality. Walton et al. (2019) define privilege as "receiving unearned social, cultural, economic, and political advantages due to alignment with specific sociocultural identity markers ... People have privilege when their identity aligns with socially constructed assumptions about what it means to be "normal'” (p. 83). For example, a White, able-bodied, cis-gendered, middleclass man has a large amount of privilege and is extremely advantaged because his various identities align with cultural norms. He is privileged because his various identities are favored by society and the institutions he operates in. Privilege greatly affects how we see the world and how we interact with those around us. We must actively interrogate our own privilege, as it is often difficult for those of us with large amounts of privilege to see how we are advantaged and others-especially those who are multiply marginalized-are disadvantaged. When we acknowledge our own privilege, we can begin to consider the ways that we might empower others.

Power is inextricably connected to our positionality and privilege. Walton et al. (2019) argue that "[b]oth positionality and privilege affect the margin of maneuverability for any individual actants, and both function across domains of power. Without an articulation of those domains, we may fall short of the ways we are collectively and personally responsible for how we empower and disempower others through our work in the classroom, public sphere, corporate sphere, and discipline” (p. 126). In other words, we must acknowledge our positionality and privilege before we can understand the ways we have been complicit in the oppression of others. Ultimately, Walton et al. (2019) put forward the 3 P's model so that we may begin to interrogate 
oppressive structures and interrogate our own complicity in sustaining structures that maintain our privileges. This model allows us, as TPC teacher-scholars, to interrogate the institutions we work in and the discipline as a whole so that we can empower teacher-scholars and students who have been historically marginalized. Extending Walton et al.'s (2019) model and contemporary TPC scholarship, I build my own theoretical and methodological framework.

\section{Theoretical and Methodological Framework}

In the following sections, I further explain the two cultural-rhetorical theories that inform my thesis: feminist disability theory and critical race theory. It is from these theories that I build a methodological framework, or an FDC approach to teaching collaboration in TPC.

\section{Feminist Disability Theory}

The first theory influencing my framework is feminist disability theory (FDT). Garland-Thomson (2011) is credited with explicitly bringing together feminist theory and disability theory in her article "Integrating Disability, Transforming Feminist Theory." However, FDT is not merely bridging two academic fields of inquiry. As Hall (2011) notes, "understanding feminist disability studies as simply a combination of feminism and disability studies dulls its critical edge and lessens its potential to intervene in theoretical and social transformation" (p. 1). FDT is not intended to narrow the feminist or disability lines of inquiry in any way.

On the contrary, FDT is concerned with larger social issues, specifically the tie between normalcy and identity construction (Dolmage \& Lewiecki-Wilson, 2010; Garland-Thomson, 2011). Garland-Thomson (2011) suggests the goal of FDT "is to augment the terms and confront the limits of how we understand human diversity, the 
materiality of the body, multiculturalism, and the social formations that interpret bodily differences" (p. 15). Garland-Thomson (2011) recognizes that the ways in which we categorize and differentiate human bodies is a sociopolitical construction. Similarly, Dolmage and Lewiecki-Wilson (2010) argue we must "actively interrogate the assumption that the [W]hite, male, and able-bodied position is central and natural," as this position is based in "a set of particular hegemonic values, instituted and maintained by a ruling class that excludes many" (pp. 25-26). From there, they challenge the concepts of "bodily difference" and "abnormality" from a rhetorical standpoint to examine language practices that produce-and reproduce-normalizing categories. FDT, then, allows us to consider how certain bodies are marked and assigned meanings and how those meanings are based in sociopolitical constructions of normalcy.

FDT has recently been used as a theoretical framework by teacher-scholars in the field of TPC (Moeller, 2018; Smyser-Fauble, 2018). Moeller (2018) argues that FDT is important for TPC teacher-scholars because it "calls attention to bodies that comprise the margins, to the disempowerment and disfranchisement of various populations of individuals often found outside of or bastardized by the cultural 'norm”' (p. 213). Similarly, Smyser-Fauble (2018) argues that FDT is an important theoretical framework because it considers lived, human embodiment and makes "more apparent the value of embodied experiential knowledges" (p. 75). Drawing from these scholars, I understand FDT as a framework that: (1) critiques sociopolitical constructions of normalcy, (2) recognizes the individuals that have been marginalized by constructions of normalcy, and (3) values the lived experiences and knowledges of these underrepresented individuals. This framework allows me to consider the embodiment of teacher-scholars and students, the concept of normalcy, and how they connect to collaboration in the 
TPC classroom, specifically collaborations between those who are traditionally privileged and those who are marginalized in this academic space.

\section{Critical Race Theory}

While FDT is a valuable methodological framework, it is important to recognize that both feminist and disability studies have a history of Whitewashing and leaving out BIPOC. In his article “Is Disability Studies Actually White Disability Studies?”, Bell (2017) raises concerns about this issue. Bell (2017) argues that White scholars constantly cite each other, "revealing an uncomfortable incestuousness about Disability Studies" (p. 409). He claims the field "has a tenuous relationship with race and ethnicity," as it has excluded BIPOC and neglected to bring their voices and experiences to the forefront (Bell, 2017, p. 409). Similarly, Haas (2012) argues the TPC field "also has a history of ignoring the ways in which our work is saturated with [W]hite male culture-which has real effects related to privilege and oppression on the lives and work of designers, writers, editors, and audiences of technical communication" (p. 284). With these issues in mind, I believe it is important-and necessary-to combine FDT with a theory that explicitly brings race and ethnicity to the forefront. For this reason, I will be drawing from critical race theory as well.

Critical race theory (CRT) was first crafted by Patricia Williams, Derrick Bell, and Alan Freeman in the 1970s. As law professors, these three scholars "created CRT to highlight systemic problems. By connecting feminism and legal indeterminacy, the scholars were able to craft five basic tenets to characterize CRT as an accessible theory in law:" (1) ordinariness, (2) interest convergence or material determinism, (3) social construction, (4) differential racialization, and (5) legal storytelling (Edwards, 2018, p.

273). These five tenets were eventually taken up by scholars in other fields and used to 
examine structural racism and consider the connections between language, social structures, race, and power. Recently, scholars have taken CRT and combined it with disability studies to form dis/ability critical race studies—or DisCrit (Annamma, Connor, \& Ferri, 2013). Drawing from CRT, Annamma et al. (2013) propose key tenets of DisCrit that center around race and disability in academic institutions. They argue that a "DisCrit theory in education is a framework that theorizes about the ways in which race, racism, dis/ability and ableism are built into the interactions, procedures, discourses, and institutions of education" (p. 7). In this way, DisCrit allows me to consider institutional racism and ableism in an academic setting. However, it is important to note that DisCrit is not explicitly feminist. For this reason, I combine FDT with DisCrit in order to build a methodological framework that considers theories of race, disability, and feminism. More specifically, I build this methodology-an FDC approach to teaching collaboration in TPC-to account for students with varying embodiments and improve their collaborative experiences in PWIs.

\section{Tenets of Feminist DisCrit}

Drawing from contemporary TPC scholarship, Jones et al.'s (2016) 3P's model, FDT, and CRT, an FDC approach acts as a methodology for TPC teacher-scholars working in PWIs. More specifically, I have built FDC as a methodology to encourage socially just student interactions and collaborations in predominantly White settings. For this reason, an FDC approach subscribes to these key pedagogical tenets:

1. Teacher-scholars recognize-and urge students to recognize-that identities are intersectional, and those who are multiply marginalized are dealing with distinct but interlocking oppressive structures, which affect the ways they can operate and interact within PWIs. 
2. Teacher-scholars acknowledge and make clear to students the ways certain embodiments are normalized by overlapping systems of racism, ableism, and sexism and how certain ways of interacting sustain social norms that benefit those in privileged positions.

3. Teacher-scholars encourage students to consider how we can interact differently and model the ways we might interact differently by interfering in the core curriculum and privileging the experiential knowledges of historically marginalized scholars and students.

4. Teacher-scholars acknowledge their own positionality, privilege, and power, model this approach for students, and encourage students to do the same in order to work toward more positive interactions and collaborations in the classroom and beyond.

\section{Positionality, Privilege, and Power as a Researcher}

In order to engage with and apply the cultural-rhetorical theories that inform an FDC methodology and tenets, I must first do what Jones et al.'s (2016) 3P's model calls on me to do-examine my own positionality, privilege, and power as a researcher. Jones et al. (2016) call on researchers to consider the "ways that the researcher's and others' subjectivity is shaped by and shapes the research project" and how "aspects of my identity shape the way I think about research" (p. 12). I am a White, able-bodied, cisgender, female. I come from an upper middle-class family, which has given me access to higher education. For this reason, I am multiply privileged in academic spaces, and I do not face the same physical, emotional, and social experience of being marginalized as many others do. However, as Walton et al. (2019) argue, positionality "is a useful lens for seeing other people more fully, more complexly, and more respectfully” (p. 79). 
While I may never fully understand another's positionality, I am willing to listen, to learn, to be corrected, and to change my research and pedagogical practices, which is part of what I aim to do and encourage others to do in this thesis.

My positionality, then, results in unearned privileges, which changes the way I conduct research and enact power within my research. Jones et al. (2016) argue that researchers must examine their privileges and seek "to understand the way unequal opportunity shapes or reflects both the questions asked and the results of the study" (p. 11). It is important for me to acknowledge that "diversity" research conducted by people in privileged positions similar to my own has been historically harmful and has mainly served to sustain our privileges politically and socially. As Walton et al. (2019) note:

[T]here has been a great deal of research about what privilege is and how it functions, specifically in the U.S. However, much of this research has originated from scholars who are in positions of privilege due to their sociocultural identity markers. In other words, individuals at the center have theorized about what it must be like to be an individual or group at the margins. (p. 85)

Due to this history, I want to be transparent about the work I am trying to do in this thesis. I am not trying to speculate about what the experience of being marginalized might be like, and I am not trying to offer empty "solutions" to those who are historically marginalized. Rather, I am intentionally framing this research project as the work that needs to be done for me to engage-and encourage dominant-identified scholars and students in PWIs to engage-in conversations about race, disability, and gender in order to work toward more inclusive interactions and collaborative experiences across and between groups with varying embodiments. Instead of relying on historically marginalized groups to carve out space for themselves or cater to the majority, this 
thesis aims to consider the ways dominant-identified teacher-scholars and students might use their privilege and power to work toward more socially just interactions and collaborations.

\section{Chapter Overview}

Now that I have established my theoretical and methodological foundations, I will briefly outline the two chapters that follow.

In chapter two, I consider the following questions: What do TPC teacher-scholars know about collaborative work, and how do they address conflict that arises in relation to race, disability, and gender? How do White male and non-disabled normalcies impact student collaborations? I begin chapter two by reviewing the literature on student collaboration in TPC to describe and evaluate what we currently know about collaboration in the TPC classroom (England \& Brewer, 2018; Voss, 2018; Wolfe, 2010). Specifically, I review this literature to consider the ways TPC teacher-scholars are being influenced and educated about attending to student conflict in relation to race, disability, and gender. To highlight student perspectives in contrast to this theoretical work, I then use data from my IRB-approved study on the collaborative experiences of TPC students. The aim of using this data is to incorporate TPC students' experiential knowledges and attitudes toward collaborative work in the classroom. I then apply an FDC methodology to this scholarship and data in order to consider where conflict arises-specifically with a focus on student conflict in relation to enactments of privilege to sustain White male and non-disabled normalcies. Finally, I conclude chapter two by considering how TPC teacher-scholars might challenge dominant-identified students' normative comfort to work toward more positive collaborations in the TPC classroom. 
In chapter three, I pose the following question: Drawing from the FDC methodology and extending chapter two's work on student conflict, what could a team contract for a TPC course in a PWI look like? I begin chapter three by focusing on team contracts as a method for encouraging collaboration. Specifically, I consider how team contracts can attend to issues dominant-identified students need to think about when participating in collaborations with students from historically marginalized groups. I then employ an FDC framework and draw from the scholarship and data in chapter two to create an infrastructure for building a team contract handout. I consider foundational questions and concerns TPC teacher-scholars in PWIs would need to ask when creating a team contract handout, while still leaving space for student considerations and different institutional contexts. Finally, I create an example of a team contract handout situated within the context of ISU's Technical Writing I \& II courses. This handout is meant to serve as an example within one institutional context and is not meant to be an exportable template, as team contracts are highly contextual. I conclude this thesis as a whole by considering the larger impacts studying student collaboration has for the TPC field, as well as further cultural-rhetorical and social justice work that teacher-scholars and students can take up to work toward more inclusive spaces. 


\section{CHAPTER II}

\section{INVESTIGATING COLLABORATIVE CONFLICT AND THE AVOIDANCE OF CONFLICT IN THE TPC CLASSROOM}

In the TPC field, collaboration is absolutely necessary—not only for team projects, but also to gather more perspectives from experts and stakeholders to better situate information for audiences. While it is easy to picture technical communicators isolated in tiny cubicles, this is rarely the reality of TPC. In their study on "Core Competencies for Technical Communicators," Rainey, Turner, and Dayton (2005) find "that the most important competencies for technical communicators are [s]kills in collaborating with both subject-matter experts and coworkers" (p. 323). Therefore, in order to prepare students for the TPC field, teacher-scholars must consider ways to encourage collaboration in the classroom.

In chapter one, I discussed the need for socially just cultural-rhetorical approaches to teaching TPC; I addressed how positionality, privilege, and power are undeniably intertwined; and I established four tenets for encouraging socially just student interactions in TPC classrooms. As the fourth tenet called me to do, I acknowledged my own positionality, privilege, and power as a researcher, and now I must consider how to encourage students to do the same in collaborative settings. In this chapter, I extend the work of chapter one by considering how positionality, privilege, and power impact students when they collaborate.

For this reason, I have divided this chapter into two parts. In the first portion, I review the literature on collaborative work in TPC and composition classrooms and the ways teacher-scholars have addressed student conflict that arises in relation to race, disability, and gender. Specifically, I draw from Voss' (2018) study on collaborative 
digital projects in writing classrooms to consider how dominant-identified students use their positionality, privilege, and power in collaborative settings. In the second portion, I build upon Voss' (2018) work by presenting my own pilot study on student collaboration. By using data from my pilot study, I consider how TPC students enrolled in a PWI perceive collaborative work. I then analyze these data in relation to White male and non-disabled normalcies to hypothesize the ways dominant-identified students may be upholding these norms in collaborative settings.

\section{Collaboration in the TPC Classroom}

Before I present my own pilot study, I must first consider what TPC teacherscholars know about collaborative work. Wolfe (2010) gives two main reasons why instructors might assign collaborative work:

1. “To prepare students for the workplace by providing opportunities to learn the social and organizational skills necessary for productive teamwork" (p. 5).

2. "To improve the educational experience through collaboration with fellow students. Educational research suggests that people learn the most when working with peers toward a common goal" (p. 5).

In most workplaces, teamwork and collaborative writing have become the norm because individual work is rarely as productive or insightful (England \& Brewer, 2018; Wolfe, 2010). This is especially true for technical communicators, as they regularly work in teams and consult subject-matter experts to gather accurate information. For this reason, England and Brewer (2018) argue that TPC courses must incorporate collaborative work because "[e]ffective use of collaboration supports rich and authentic contexts where students are more engaged and where their learning accurately reflects workplace contexts" (p. 159). In addition, collaboration in the TPC classroom "often 
results in superior work, learning, and retention ... Collaborative assignments can also result in learning that simply was not addressed before, or learning that is more readily transferred" (England \& Brewer, 2018, p. 173). Collaborative work gives students the opportunity to teach and learn from each other, which in turn allows student to rely on each other's expertise rather than solely on the instructor's. With that said, there is a lack of research in the TPC field that attends to student conflict in relation to race, disability, and gender-specifically student conflict and the avoidance of conflict due to enactments of privilege and power. In the following section, I establish how collaborative work differs in a classroom setting, and I draw from Voss' (2018) study on digital collaborations in writing classrooms to consider how privilege may affect student interactions.

\section{Challenges and Student Conflict in Classroom Settings}

While collaboration in the classroom has many benefits, teacher-scholars must acknowledge that it is not directly equivalent to collaboration in a workplace setting. Wolfe (2010) notes that "[u]nlike school-based teams, work-based teams can develop longer histories of working together and are more likely to have clear-cut lines of authority. Thus, school-based teams have some unique challenges that are not present in work-based teams" (pp. 5-6). Similarly, Voss (2018) comments on group structure and the difference between school-based and work-based teams, as "[s]tudents are brought together on an ad-hoc basis: they do not know each other or invest in the group's task in the way that members of self-sponsored professional writing groups do" (p. 61). For this reason, one major conflict that arises for students in collaborative settings is the abruptness of group formation. Students are often thrown into groups fairly quickly and sometimes randomly, which gives them very little time to negotiate 
their different goals and varying levels of investment. When individual learning goals are not addressed within teams, Voss (2018) argues that students rely on their antecedent knowledge-what they already know and what they're comfortable withand leave the classroom feeling like their learning has been compromised.

To examine certain points of student conflict and the antecedent knowledges students often rely on, Voss (2018) draws from Bourdieu and Passeron's concept of cultural capital. Cultural capital can be defined as

the accumulation of knowledge, behaviors, and skills that a person can tap into to demonstrate one's cultural competence and social status ... Bourdieu and Passeron asserted that the accumulation of knowledge is used to reinforce class differences. That's because variables such as race, gender, nationality, and religion often determine who has access to different forms of knowledge. Social status also frames some forms of knowledge as more valuable than others. (Cole, 2019)

By using the concept of cultural capital, Voss (2018) considers who actually learns in collaborative settings, who tends to take on specific responsibilities, and how this might further marginalize and impact the learning of historically marginalized students.

Voss (2018) begins by considering access and individual literacies. Every student has different and varying levels of literacies, and Voss (2018) argues that race, disability, and gender impact opportunity and access to digital literacies in particular. Voss (2018) notes that there is a "tendency to replicate in student groups the inequities found in society as a whole" and refers to the "digital participation gap" as an example of this (p. 59). Researchers have found that "young, White, male, wealthy, and educated individuals much more frequently create content" online while "non-White, female, 
poor, less educated, and older users tend to engage in more passive activities (such as browsing) rather than production and agentive practices like composing written or multimedia content" (Voss, 2018, pp. 59-60). Ultimately, Voss (2018) argues that this leaks into student group dynamics. Dominant-identified students who have been afforded more opportunity and access to digital literacies come into collaborative settings doubly advantaged. This then leads Voss (2018) to the question: Why are dominant-identified students more likely to take up (or take over) leadership roles?

Voss (2018) argues that dominant-identified students tend to label their privilege and access to digital literacies as "experience" or "expertise" and take up leadership roles based on their advantages. As Voss (2018) found in her case study, dominant-identified students with more cultural capital-"White, young, male, or well-educated group members"-were positioned as “"natural' fits for leadership and technical expert roles” (p. 58). This left disadvantaged or historically marginalized students in subordinate positions by default. Without renegotiating what constitutes "experience" and considering each student's personal learning goals, students relied on cultural and social norms of what constitutes a "leader." Voss (2018) found that

Some group members exerted more control over the composing task than others, setting and enforcing deadlines and altering others' work to fit the final project. And access to these roles, even as they shifted over time, were significantly shaped by the various kinds of capital-age, experience, time, and personal investment-which were the products of the racial, economic, and gender capital available to different group members. (p. 72)

In this way, dominant-identified students took on roles they were already familiar or comfortable with (i.e. the roles they had better access to), which compromised the 
group's overall learning experience and “undermin[ed] the project's potential to provide new learning opportunities" (p. 65). Through this study, Voss (2018) calls on teacherscholars and students to carefully consider individual literacies, access to those literacies, what constitutes "experience," and who is taking on leadership roles within group work. If these things are not considered and (re)negotiated, dominant-identified students may use their positionality, privilege, and power to take up leadership roles based on perceived experience alone, which limits access for historically marginalized students. To build upon Voss' (2018) work, I present data from my pilot study in the following section to consider how White male and non-disabled normalcies affect student collaborations.

\section{Pilot Study on Student Collaboration in the TPC Classroom}

In the fall semester of 2019, I conducted a study on the collaborative experiences of TPC students in a large public midwestern PWI. When I first began this study, I wanted to better understand how TPC students experience and perceive collaborative work and collaborative writing in the classroom. With this goal in mind, I crafted the following research questions:

- How do technical communication students experience collaborative work in the classroom, especially collaborative writing?

- How do students personally assess collaborative work/collaborative writing in the classroom?

- How do students determine if a collaborative experience has been positive, negative, or neutral?

These three research questions ultimately informed my decision to create a 7-question survey (see Appendix A: Survey Questions) where I asked participants to: 
- Share demographic information (including major, age, gender, race/ethnicity, and disability);

- Identify the kinds of group work they had previously participated in;

- Share specific instances or stories regarding their collaborative work and collaborative writing experiences;

- Rate their overall experience with collaborative work and collaborative writing in a classroom setting.

I specifically decided on a Qualtrics survey as my method of data collection because it allowed me to ask students about their experiences in a totally anonymous way. Since I would be surveying students who did not know me, I suspected that they would be more comfortable sharing their collaborative experiences-positive or negative-in an anonymous online setting.

\section{Participants}

After my study was approved by the IRB4, I distributed the survey to 28 students who were currently enrolled in either English 249: Technical Writing I or English 349: Technical Writing II. These participants are mixed majors with a large majority being outside of the English department (See Appendix B, Chart 1: Participants by Major). Because I surveyed both English 249 and 349, these participants are a mix of undergraduate and graduate students between the ages of 19-30. Additionally, these participants had taken one or two TPC courses in the past, so I knew they would have a unique perspective on collaborative work in the classroom and would be able to answer my research questions.

\footnotetext{
4 Illinois State University IRB-2019-481
} 
It is important to note that I intentionally made Question 1 (the demographic section) into short answer fields, which allowed participants to self-identify as they normally would or leave the field blank if they did not want to disclose certain demographic information. With that said, a majority of participants self-identified as female5 (See Appendix B, Chart 2: Participants by Gender). Due to the fact that I conducted this study in a PWI, unsurprisingly, a majority of participants self-identified as White (See Appendix B, Chart 3: Participants by Race/Ethnicity). Finally, a majority of participants self-identified as non-disabled (See Appendix B, Chart 4: Participants by Disability).

\section{Coding and Data Analysis}

In this survey, I collected both qualitative and quantitative data. In Question 3 and Question 6, I asked participants to share a specific story or instance that came to mind regarding group work and group writing (qualitative data). Then, in Question 4 and Question 7, I asked participants to rank their overall experience with group work and group writing as positive, neutral, or negative (quantitative data). I specifically asked for the qualitative data first because I did not want the quantitative ranking to affect or change the stories participants wanted to share. For example, if participants ranked their overall experience as positive first, then they might be more likely to share a positive story following that ranking. In Question 3 and Question 4, I asked participants about group work in general. In Question 6 and Question 7, I specifically asked participants about group writing, which I defined in Question 5 as producing a

\footnotetext{
5 In a future study, I would like to give more attention to the differences between how individuals identify demographically versus how they identify in terms of positionality.
} 
written document with one or more team members. In the following subsections, I will share my coding and data analysis of the qualitative data I received.

To protect student anonymity, I refer to participants as P1, P2, P3, etc. I also refer to questions as Q1, Q2, Q3, etc. in the following sections. In my coding and data analysis that follows, I exclusively use in vivo codes-which are words or short phrases taken directly from participants-to preserve students' authentic experiences and empower student voices. In analyzing these in vivo codes, my goal is to understand students' genuine concerns in the context of a PWI. Specifically, I emphasize how students' responses to collaborative work may be read as reproducing White male and nondisabled normalcies, which then impacts how students are able to collaborate and engage with each other.

\section{Lack of Control and Comfort in Collaborative Work}

From the qualitative data I collected in Q3, eleven participants expressed that group work can be a "hit or miss" experience or an experience largely based on "luck." The in vivo code "hit or miss" emerged from P2 and P26. P2 noted that "Group work in the classroom setting can be hit or miss." Similarly, P26 wrote that "Overall, working in groups has been hit or miss." I thought it was interesting that two participants specifically used the phrasing "hit or miss," so this became an in vivo code for group work that has varied drastically depending on the peers that participants are paired with. As P27 wrote, group work "depend[s] on the nature of the task and the composition of the group."

This "hit or miss" code also represents participants who felt their group work experiences have been based on luck and largely out of their control. For example, P2O wrote that "My experiences with group work have been strange and varied. Sometimes, 
groups just so happen to have an amazing dynamic and get great work done! ... Other times, I'm not as lucky." Similarly, P3 wrote that "The experience of group work in a classroom setting all depends on the people in your group. Sometimes, and this is a BIG sometimes, you have a perfect group where everyone does all the work they need to do and on time." Here, participants specifically attribute group dynamics to luck and express that these dynamics are random and uncontrollable.

In Q3, participants also expressed their collaborative experiences by using two metaphors in particular-"falls short of their work" and "does not pull their weight." The in vivo codes "falls short of their work" and "does not pull their weight" emerged because participants felt they took on more responsibility than their group members, or more responsibility “fell” on them because group members weren't “pulling their weight.” This grouping of codes specifically deals with a lack of contribution from other group members, so participants were left feeling frustrated and overwhelmed with the amount of work they had to take on by themselves. In total, I have placed sixteen participants under this grouping of codes because they used similar language to describe their experiences with other group members.

I was specifically interested in the metaphors of "falling" and "pulling," which refer to group work as a physical, embodied experience. Three participants used "fall" as a metaphor:

- P2: "Group work ... tends to fall on certain members."

- $\mathrm{P}_{3}$ : “ $[\mathrm{M}]$ ost of the time there is at least one person who falls short of their work in one way or another."

- P8: "Most of the work at the end of the project fell into my lap." 
In these cases, participants used "fall" as a metaphor to indicate that the experience was out of their control. Group members did not complete their work, so participants felt they were forced to take up additional responsibilities. Similarly, two participants used "pull their weight" as a metaphor:

- P4: "There is always someone who does not pull their weight in the group and it requires others to take up more work than planned."

- P15: "I think that group work goes well when everyone is on the same page and everyone is pulling their weight for the work."

In these cases, participants were concerned with equality and group members who did not do their "fair" share.

The data from Q3 led me to wonder what constitutes "a perfect group" or "an amazing group dynamic"? These participants seemed to be looking for more control and comfort in their collaborative experiences-specifically in the peers they are assigned to work with-which might be read as the imperative for control and comfort to maintain normalcies and privileges. Potapchuk et al. (2012) note that "White culture assigns a higher value to some ways of behaving than others. It often defines the 'other' behaviors as dangerous and/or deviant." Essentially, Potapchuk et al. (2012) argue that White culture avoids racial conflict in order to be "polite" and remain comfortable. This results in dominant-identified students being uncomfortable with conversations about positionality, privilege, and power and ultimately unable to engage with historically marginalized peers. Participants' "luck of the draw" mentality could be read as the luck of retaining White comfort and avoiding racial conflict in group settings. This argument could easily be extended to other intersectional complexities. Are students with disabilities who collaborate through non-normative means being labeled as "strange" or 
"unlucky" group members? Are non-binary or female students in a predominantly male group being read as "strange" or "unlucky"? Are students who identify as multiply marginalized being marked as "strange" or "unlucky" by dominant-identified group members? Ultimately, it might be easier for dominant-identified students to blame luck if they feel uncomfortable rather than stepping out of their privileged comfort zones to acknowledge conflict caused by White male and non-disabled normalcies. This may not be the case for every participant in this study, but "luck" could be used as a catch-all excuse to avoid addressing conflict that arises due to race, disability, and gender.

I also find it significant that participants attempted to express their negative collaborative experiences in metaphors-especially metaphors that deal with physical acts like falling and pulling. When examining the metaphor of falling, it is important to note that participants expressed group members often fall short of their designated workload or do not contribute enough. This leads to questions like: What are the characteristics of an "effective" team member? How do students gauge if team members are doing "enough" or "falling short of their work"? As Potapchuk et al. (2012) note, "White culture defines what is considered normal-it creates the standard for judging values." Therefore, dominant-identified students are likely to define what is considered to be a normal workload and hold all team members to this standard. This is true in feminist and disability studies as well. Scholars such as Price (2009) and Cedillo (2018) argue that being "ready and able" to engage and collaborate changes for every individual from moment to moment, and we must constantly "make room for bodily diversity" (Price, 2009, p. 13; Cedillo, 2018, p. 1). As Cedillo (2018) notes, "All bodies are not identical; neither are their needs, expressions of movement, or preferred modes of reception" (p. 4). The expectation that all students must be equally "productive" in any 
given moment is a racist, ableist, and sexist one that reinscribes dangerous norms and sustains normative (White, male, and able-bodied) privileges. These normalized expectations for productivity set teams up for failure, as many students-even students with certain privileges-have unique bodies that cannot conform to the expectations set by White male and non-disabled culture.

Additionally, the metaphor of "pulling" suggests that students view collaborative work as a mental and physical activity that is both emotionally and physically taxing. In other words, participants in this study describe collaborative work as an embodied experience that goes beyond cognitive labor, as team members are expected to pull their own weight and sometimes pull the weight of others. ${ }^{6}$ Potapchuk et al. (2012) argue that "White culture values certain ways of knowing and not others." In this case, White culture and the academy (which are undeniably intertwined) value cognitive work over physical labor. White culture has set the expectation that universities should be about the mind. Therefore, the body and embodied knowledges are often devalued. Similarly, Cedillo (2018) argues that embodied knowledges are "often met with resistance in the academy," as emotional appeals and personal experiences are not considered to be "appropriate" or "valuable" in this academic space (p. 2). With this normalized expectation of mind over body, dominant-identified students in privileged positions may view the physical aspect of collaborative work-stepping in and helping others "pull their weight"-as beneath them. Dominant-identified students may be more likely to value equality (everyone pulling their own weight) over equity (supporting others when

\footnotetext{
${ }^{6}$ In future research, I would like to spend more time studying embodiment, emotion, and affect in both team work and academic spaces in general. Specifically, I would like to investigate the ways bodies are expected to conform/perform in academic spaces and the role that emotion and affect might play in countering these sociopolitical constructions of normalcy.
} 
they are not in a position to pull their own weight). Overall, the data I gathered from Q3 points toward a kind of "luck" in retaining normative comfort and privilege. All group members are expected to perform equally and be normatively "productive" in order to avoid conflict that might reveal privilege.

\section{Collaborative Writing as Divided and Individual}

In regards to collaborative writing, three in vivo codes emerged from Q6"separate but 'group' effort," "split up," and "lacks cohesion.” Since I was asking about a particular form of group work-group writing-I set up Q6 by asking Q5: "Have you ever participated in collaborative writing (or group writing) in a classroom setting? (e.g. Have you ever produced a written document with one or more team members?).” Here, I defined group writing for participants who may have had a different definition of group writing or had not realized they had participated in group writing in the past. If participants responded that they had not been a part of a group writing project or they weren't sure if they had or not, then they were taken to the end of the survey. These participants would not be able to answer Q6 if they had not participated in group writing. Therefore, only participants who answered yes to Q5 were taken to Q6. For this reason, there were only 25 participants who responded to Q6, as three participants opted out.

Based on my definition of collaborative writing, participants shared their collaborative writing experiences in Q6. The in vivo code "separate but 'group' effort" emerged from $\mathrm{P}_{5}$. This participant expressed that group writing was almost always disjointed and more of an individual effort. Similarly, P22 wrote "We did not collaborate, we just sectioned off the essay to assign each other different parts. In the end we got a good grade but I didn't understand why we didn't just write a paper 
individually." Five participants specifically mentioned that group writing seemed "split" or "divided," and in total, nine participants fall under this grouping of codes. Ultimately, the codes "separate but 'group' effort" and "split up" deal with the ways in which collaborative writing is divided amongst team members-specifically divided to the point where team members are no longer communicating or collaborating with each other.

Similarly, the in vivo code "lacks cohesion" emerged from P24 who noted that group writing felt divided because the final document often lacks cohesion. P21 also noted, "With collaborative writing, people tend to split up the work so it's not so overwhelming. However, this is when the paper finds problems in its cohesiveness; not everyone has the same writing style." In total, five participants fall under this code and used similar language. Three participants were concerned with the "flow" of the final document, while two participants specifically mentioned "cohesion" as a common issue. In this way, the in vivo code "lacks cohesion" closely relates to the previous code. Participants were concerned with the cohesion of final collaborative documents because the separate sections still appeared to be individually written.

These participants complicate assumptions we often make about collaborative writing and how it operates. Collaborative writing is not automatically or inherently collaborative, as students may divide work and write individually without ever collaborating with their team. These participants have experienced and expressed that divide, which for some has led to a negative collaborative writing experience. Potapchuk et al. (2012) argue that "White culture privileges a focus on individuals (not groups). Independence and autonomy are valued and rewarded." Additionally, from a feminist and disability studies perspective, collaborative work is relational work, which has been 
feminized and historically devalued (Dolmage, 2009; Garland-Thomson, 2011). Since individuality is a norm in White male and non-disabled culture, dominant-identified students may feel discomfort in relying on group members to complete a project collaboratively. For this reason, dominant-identified students may try to re-center themselves and take over a project-or certain parts of a project-in an attempt to make it more individual.

\section{Student Solutions to Collaborative Complications}

While the above sections deal more with participants' negative collaborative experiences, participants also expressed positive experiences and articulated what made those experiences positive for them. Specifically, the in vivo codes "smaller groups," "Google Docs," and "simultaneous collaboration" emerged. The in vivo code "smaller groups" emerged from P9, P18, and P24, who directly link positive group work experiences to smaller groups:

- P9: "With group work that includes usually three or more people, I feel as if there is always one or more people who do not contribute substantially to the work/project. I think this happens because they assume the other two or more people can do it instead of being held more accountable by one person."

- P18: "I have had good experiences with working in smaller groups of three students. I believe smaller groups allow for work to be evenly shared among group members.”

- P24: "Generally, with work and discussions that are done in class in small numbers, I have a positive experience. However, in larger groups (especially 4) and those that meet outside of the classroom, I have had a large amount of negative experiences.” 
In these three cases, participants linked positive experiences to smaller groups and negative experiences to larger groups. In total, there were nine participants who expressed positive experiences in smaller groups and fall under this code. Overall, participants considered smaller groups to be more productive in terms of communication and participation.

Surprisingly, the in vivo code "Google Docs" was specifically mentioned by five participants, and each participant spoke positively about the platform. P19 wrote that “we ... work simultaneously on a Google Doc until it's complete, spot checking each other's work as we go along. Simultaneous collaboration is my favorite form of group work." These participants specifically valued Google Docs because it gave them the ability to collaborate simultaneously-or read, write, and comment on the same document at the same time-which made their group writing experiences more positive. These codes suggest that students would prefer to work in smaller groups and would prefer to work on a platform that allows for simultaneous, real-time collaboration, as students believe these group settings encourage higher levels of participation.

However, it is important to note that these results emerge from mostly dominantidentified students in a PWI, so these suggestions might be read as an attempt to return to normative comfort. If we take these "solutions" at face value and directly import them into our classes, then we risk reinscribing White and normative comfort. As teacherscholars working toward more socially just interactions and collaborations across and between students with varying embodiments, it is critical for us to examine these "solutions" and their affordances and constraints in our specific institutional contexts and classrooms. This ties back to Voss' (2018) argument; we need to be considering individual literacies and access to those literacies for each class and student we teach. 
As I have done in my coding and data analysis above, we need to be interrogating data that emerge from dominant-identified students in relation to White male and nondisabled normalcies rather than directly transferring that data as sound pedagogical solutions.

From Voss' (2018) study and my own pilot study, it is clear that White male and non-disabled normalcies permeate the classroom and therefore impact student collaborations. When reading student concerns in the context of a PWI, teacher-scholars can better understand how dominant-identified students are likely to use their privilege and exert control/power in collaborative settings in order to maintain comfort. With these issues in mind, I move to chapter three, where I consider methods for encouraging more inclusive and socially just collaborations in the classroom. I begin by considering grading contracts (Danielewicz \& Elbow, 2009; Inoue, 2012; Litterio, 2016; Medina \& Walker, 2018; Spidell \& Thelin, 2006) in relation to team contracts (Wolfe, 2010). Ultimately, I argue team contracts are more effective in PWIs, given my explicit interest in developing a method that requires dominant-identified students to interrogate their privileges, the ways they understand collaboration, and the ways they engage with historically marginalized peers. I conclude chapter three by offering an infrastructure for developing a team contract handout and creating an example of a team contract handout situated within the context of ISU's Technical Writing I \& II courses. While this is not meant to be an exportable pedagogical tool, this infrastructure and example may help TPC teacher-scholars consider team contracts in their own institutional contexts and classrooms. 


\section{CHAPTER III}

\section{TEAM CONTRACTS AS A METHOD FOR SOCIALLY JUST STUDENT COLLABORATIONS}

When asking students to take on a collaborative project, it is crucial to define collaboration-what it is, what it should do, and what "effective" or "ineffective" collaboration might look like in the context of this specific classroom and project. As England and Brewer (2018) note, "some parts of your course must be given to preparing students to write collaboratively in realistic, complex contexts" (p. 160). Therefore, preliminary discussions with students as the primary stakeholders are necessary before beginning any kind of collaborative project. Without these initial negotiations that set shared expectations, TPC teacher-scholars risk (re)producing inequities of race, disability, and gender among student groups and (re)inscribing White male and nondisabled normalcies in their classrooms.

In chapter two, I reviewed the literature on collaborative work in TPC and composition classrooms and the ways teacher-scholars have studied and addressed student conflict in relation to race, disability, and gender (England \& Brewer, 2018; Voss, 2018; Wolfe, 2010). I then presented data from my own pilot study on student collaboration in the TPC classroom in order to hypothesize the ways dominantidentified students might be upholding White male and non-disabled normalcies in collaborative settings. In this chapter, I extend the work of chapter two by considering methods that TPC teacher-scholars might employ to encourage more socially just interactions and collaborations between students. Specifically, I focus on team contracts as a potential method in PWIs that requires dominant-identified students to interrogate their privileges, implicit biases, and understandings of collaborative norms. 
As such, I have divided this chapter into five parts. In the first portion, I consider two methods for encouraging collaboration in classroom settings: grading contracts and team contracts. I then examine the ways team contracts are more beneficial in PWIs and further the social justice turn in TPC. In the second portion, I provide a general infrastructure for developing team contract handouts based on the FDC framework and tenets I set forth in chapter one. This infrastructure includes important questions TPC teacher-scholars must ask when planning team contract handouts. In the third portion, I create an example of a team contract handout situated within the context of ISU's Technical Writing I \& II courses to show what a team contract might look like in a specific institutional context. In the fourth portion, I consider the limitations of my approach to team contracts as a way to identify work that still needs to be done to promote socially just and inclusive student collaborations in the TPC classroom. Finally, I conclude this chapter and this thesis as a whole by affirming the importance of socially just cultural-rhetorical approaches to teaching TPC and my commitments as an aspiring teacher-scholar of TPC and cultural rhetorics.

\section{Methods for Encouraging Student Collaboration}

Before I dive into team contracts, I must first establish why I've chosen team contracts over grading contracts. There is a great deal of research on grading contracts and a distinct lack of research on team contracts in the TPC and composition fields, which may make grading contracts seem like the preferred option. However, in the subsections that follow, I review the two methods and argue that team contracts may be more beneficial in PWIs, as team contracts require students to engage with each other to articulate their individual learning goals and the ways they might support each other to meet these goals. 


\section{Grading Contracts}

One method used to enact student-centered, inclusive learning is through the use of grading contracts. Essentially, grading contracts deal with assessment (Danielewicz \& Elbow, 2009; Inoue, 2012; Litterio, 2016; Medina \& Walker, 2018; Spidell \& Thelin, 2006). Students and the instructor have a conversation about what they value in a collaborative project and how grading should be conducted to reflect those shared values. Both Inoue (2012) and Medina and Walker (2018) believe grading contracts are a way to destabilize privilege in the classroom and avoid exclusion by negotiating assessment practices. Medina and Walker (2018) argue that "grading contracts can potentially serve as a site to facilitate a conversation about the values students and teachers should be held to and how we might use the teacher/student dynamic to faithfully represent these values throughout the course of the semester" (p. 48). Grading contracts do not necessarily encourage collaboration between team members, but grading contracts might reassure students who are concerned about their personal grade in a team setting. However, if TPC teacher-scholars do not deliberately enact socially just means of grading contract negotiation, then students may rely on past educational experiences (e.g. relying on educational standardizations of English or believing they can only meet a certain grading standard). In this way, grading contracts may reinforce disparities and educational inequities if they are not intentionally paired with social justice pedagogical approaches. While assessment can certainly be tied to the conversation surrounding student collaboration, I am steering away from the study of assessment because I am more interested in the ways that TPC teacher-scholars might foster collaboration between students and encourage dominant-identified students to challenge their privileges without grading as an incentive. 


\section{Team Contracts}

A method for addressing student conflict and encouraging collaboration between students that is not directly tied to assessment is through the use of team charters or team contracts. Wolfe (2010) defines a team charter as

a brief, informal document that describes the "big picture" goals and priorities of the project. The official purpose of a team charter is to have a written statement of the team's priorities and norms that the team can use to resolve any problems or confusion that may occur later in the project. The unofficial purpose, particularly when team members have not worked together before, is to air any differences that they might have in goals, expectations, and commitment levels before the project begins. (p. 28)

While teacher-scholars can plan and build the team contract handout beforehand, students complete the handout based on their teams' needs, which results in a unique contract. Team contracts allow student groups to decide together what constitutes success, how they measure success, what they value in the project or want out of the project, and how much they are willing to invest in the project. Team contracts also ask student groups to consider factors that might affect performance, how they will resolve differences, and how they will handle late or unfinished work (Wolfe, 2010). I am intentionally shifting away from grading contracts and moving toward team contracts because FDC-informed team contracts specifically address the following concerns:

1. Team contracts can help students articulate their individual learning goals, their collective learning goals, and how they might encourage and support each other to meet both individual and team learning goals. 
2. Team contracts can help students negotiate individual literacies and access to technologies, which requires dominant-identified students to account for their positionality and privilege.

3. Team contracts can help students negotiate the division of labor and what they can realistically take on, which allows students to consider varying abilities and levels of investment.

4. Finally, team contracts can help students decide who is taking on leadership roles and why based on individual and team learning goals.

Combined with an FDC methodology, team contracts can be more effective for TPC teacher-scholars-especially those operating in PWIs-who want to enact socially just pedagogies. With an FDC approach in mind, I move to the next section, where I provide an infrastructure for building a team contract handout. This infrastructure considers foundational questions TPC teacher-scholars in PWIs would need to ask when planning team contract handouts. Building this kind of infrastructure before providing a concrete example of a team contract is crucial, as it is more flexible and leaves space for student considerations and institutional contexts.

\section{General Infrastructure for Building a Team Contract}

When planning a collaborative classroom project, there are so many factors to take into consideration that it can become overwhelming. One key consideration for TPC teacher-scholars is: How do I encourage student collaboration? More specifically, in a PWI, how do I encourage dominant-identified students to interrogate their privileges and implicit biases in order to develop more equitable and inclusive 
relationships with historically marginalized students?7 Team contracts may be one method to prevent dominant-identified students from perpetuating racist, ableist, and sexist violences in their interactions with others, but TPC teacher-scholars must consider their unique institutional and classroom contexts to decide if a team contract is the best option. Additionally, TPC teacher-scholars must consider what a team contract might look like for their specific set of students, as each class is different and may require a living handout that is consistently tailored to the individualized needs of the students in that class. For this reason, I have provided an infrastructure for TPC teacher-scholars to plan and build team contract handouts (See Table 1). In this table, I address specific features of team contract planning and corresponding questions for TPC teacher-scholars to consider when building a team contract handout for their unique classrooms and projects. However, it is important to note that this infrastructure is not an exhaustive list of questions and is merely a starting point for TPC teacherscholars to create their own situated team contract handout. Students are then able to fill in this handout and make it their own unique contract by including elements that reflect their teams' individualized needs. In the following paragraphs, I explain Table 1 and why these features and questions are necessary for TPC teacher-scholars to consider when building a team contract handout tailored to a specific institutional or classroom setting.

For the first two features of team contract planning-"Institutional \& Classroom Contexts" and "Project Details \& Investment"-I drew from Wolfe (2010), who acknowledges that team contracts are highly situational and "differ greatly in content

\footnotetext{
7 TPC teacher-scholars must interrogate their own privileges and implicit biases as well. As tenet four of an FDC approach calls on us to do, we must model this behavior for students. We cannot ask students to do what we are not also willing to do ourselves.
} 
Table 1: Infrastructure for TPC Teacher-Scholars to Plan Team Contract Handouts.

\begin{tabular}{|c|c|}
\hline $\begin{array}{c}\text { Features of } \\
\text { Team } \\
\text { Contract } \\
\text { Planning } \\
\end{array}$ & Questions to Inform and Guide Team Contract Handout \\
\hline $\begin{array}{c}\text { Institutional \& } \\
\text { Classroom } \\
\text { Contexts }\end{array}$ & $\begin{array}{l}\text { - Am I in a PWI? Or, does my class contain a large number of dominant- } \\
\text { identified students? } \\
\text { - How will I take historically marginalized students into account? } \\
\text { - How will I ask dominant-identified students to acknowledge oppressive } \\
\text { structures, interrogate their privileges and implicit biases, and engage with } \\
\text { historically marginalized students within their teams? }\end{array}$ \\
\hline $\begin{array}{l}\text { Project Details } \\
\text { \& Investment }\end{array}$ & $\begin{array}{l}\text { - What is the collaborative project? How long will the project take? } \\
\text { - How invested might students be? How might this level of investment impact } \\
\text { student interactions? } \\
\text { - How will I ask students to articulate how invested they are and how much time } \\
\text { they can realistically put into this project? } \\
\text { - How will I ask teams to account for varying embodiments, abilities, time } \\
\text { constraints, and levels of investment? }\end{array}$ \\
\hline $\begin{array}{c}\text { Goals \& } \\
\text { Commitments }\end{array}$ & $\begin{array}{l}\text { - How will I ask students to articulate individual learning goals and what new } \\
\text { knowledge they want to gain from this collaborative project? } \\
\text { - How will I ask students to set challenging, measurable, and attainable } \\
\text { commitments? } \\
\text { - How will I ask teams to articulate broader team goals and commitments? } \\
\text { - How will I ask students to support each other to meet both individual and team } \\
\text { goals and commitments? }\end{array}$ \\
\hline $\begin{array}{l}\text { Communication, } \\
\text { Technologies, } \\
\text { Literacies, \& } \\
\text { Access }\end{array}$ & $\begin{array}{l}\text { - How will students communicate inside and outside of the classroom? How will I } \\
\text { ask students to set team standards for communication? } \\
\text { - What technologies will students use for communication and for the } \\
\text { collaborative project? } \\
\text { Do all team members have access to and know how to use these technologies? If } \\
\text { not, are there alternative technologies that might work better for the entire } \\
\text { team? } \\
\text { If there are no alternative technologies, how will I ask students to support those } \\
\text { without access to or literacies of these technologies? }\end{array}$ \\
\hline $\begin{array}{l}\text { Division of } \\
\text { Labor \& } \\
\text { Leadership } \\
\text { Roles }\end{array}$ & $\begin{array}{l}\text { - How will I encourage teams to divide the labor equitably-customizing the } \\
\text { division of labor to address inequities? } \\
\text { - How will I encourage dominant-identified students to recognize } \\
\text { emotional/relational work as important forms of labor and contribution? } \\
\text { - For this project, are leadership roles necessary? If so, how will I ask teams to } \\
\text { assign leadership roles without relying on normalized expectations of what } \\
\text { constitutes an "experienced/natural leader"? } \\
\text { - How will I ask teams to account for individual learning goals when dividing the } \\
\text { labor and assigning leadership roles? }\end{array}$ \\
\hline $\begin{array}{l}\text { Conflict } \\
\text { Resolution }\end{array}$ & $\begin{array}{l}\text { - How will I encourage students to articulate their needs, to ask for help, and to } \\
\text { - How this articulation as a strength and not a weakness? } \\
\text { - How will I ask teams to address conflict if/when it arises? } \\
\text { teams' set goals and commitments? } \\
\text { - How will I encourage dominant-identified students to view questions and } \\
\text { criticisms not as an offense but as mutually beneficial for the entire team? } \\
\text { - How will I encourage dominant-identified students to rhetorically listen to } \\
\text { other viewpoints and privilege the experiential knowledges of historically } \\
\text { marginalized students? }\end{array}$ \\
\hline
\end{tabular}


and format depending on the type of organization and project” (p. 28). Wolfe (2010) also notes the importance of varying investment levels, arguing that "team members have responsibilities outside of the project and different levels of commitment and internal motivation" (p. 32). However, the questions I have posed in these categories take a firm social justice stance by focusing on how TPC teacher-scholars might account for historically marginalized students and hold accountable dominant-identified students in their team contracts. Here, I build upon Wolfe's (2010) initial work on team contracts by taking an FDC approach and acknowledging race, disability, gender, and the intersections between and within. I believe it is crucial to consider classroom demographics and how dominant-identified students might be asked to interrogate their privileges. It is also important to consider how students might articulate their personal levels of investment. TPC teacher-scholars and students must recognize that varying levels of investment are perfectly okay. Every student is unique, and we might not know what is going on in their life. By asking students to set personal and realistic investment levels, we begin the work of normalizing varying abilities and countering White male and non-disabled expectations of productivity.

For the next three features-“Goals \& Commitments," "Communication, Technologies, Literacies, \& Access," and “Division of Labor \& Leadership Roles”-I specifically drew from Voss' (2018) study. Voss (2018) initially cites Wolfe (2010) and echoes the importance of having students set individual learning goals for collaborative projects. However, Voss (2018) specifically argues that teacher-scholars should "discourage low-road transfer, emphasizing that even experienced writers still have much to learn" (p. 62). In other words, teacher-scholars should encourage students to set goals that challenge them, "remix' prior and new knowledge," and potentially lead to 
new learning experiences (p. 62). Voss (2018) also argues that teacher-scholars must address the digital participation gap, issues of access, and varying levels of digital literacies due to inequities. As I mentioned in chapter two, it is crucial for TPC teacherscholars to acknowledge the ways that race, disability, and gender "structure opportunity" and address "the tendency to replicate in student groups the inequities found in society as a whole" (Voss, 2018, p. 59). For this reason, TPC teacher-scholars must encourage dominant-identified students to challenge their understandings of what traditionally constitutes "labor" and recognize that physical or intellectual labor is not inherently better or more valuable in group settings. We must value and privilege the contributions othered in academic spaces, including the emotional and relational labor that is too often conducted by historically marginalized teacher-scholars and students. ${ }^{8}$ Additionally, TPC teacher-scholars must encourage students to support each other to meet their individual goals and to find ways to divide labor and leadership roles more equitably. It is important to ask students how they might better support each other to work toward both individual and team goals and to counter normalized expectations of what constitutes an "experienced" or "natural" leader.

For the last feature-“Conflict Resolution”-I again consulted Wolfe (2010), who considers different kinds of conflict that tend to occur within student group work and the differences between destructive and constructive conflict (pp. 51-54). However, her suggestions regarding conflict resolution do not specifically mention conflict in relation to race and disability. Wolfe (2010) does have a short chapter on communication norms,

\footnotetext{
${ }^{8}$ In future research, I would like to spend more time studying the divide between physical/intellectual labor and emotional/relational labor. I'm interested in how those of us who are dominant-identified in specific ways might better understand and value the emotional/relational labor that is too often eliminated from academic spaces or left to those who are historically marginalized. This might be tied to footnote 6 and combined with studies of embodiment, emotion, and affect in academic spaces.
} 
where she briefly discusses communication norms in relation to gender, but this chapter does not take other positionalities into account. Ten years later, it is crucial for TPC teacher-scholars to account for all positionalities, the intersections between and within them, and how we might encourage more positive interactions. For this reason, I have built upon Wolfe's (2010) ideas of constructive conflict to include how TPC teacherscholars might encourage dominant-identified students to better understand questions and criticisms and rhetorically listen to and privilege the experiential knowledges of historically marginalized students. Based on these six features of team contract planning, I move to the next section, where I create an example of a team contract handout in a specific context to show what this process might entail.

\section{Situated Example of a Team Contract Curricular Approach}

At ISU, there are two technical writing courses (English 249: Technical Writing I and English 349: Technical Writing II) that often include some kind of collaborative client project. For the sake of this example, I will situate this team contract within an ISU technical writing course that is conducting a final client project. In a previous course with Dr. Angela Haas (English 452: The Teaching of Technical Writing), I constructed an English 249 course plan, which included a client project assignment sheet (See Appendix C). This client project will serve as the context for the following team contract.

It is important to note that this client project would occur toward the end of the semester, so a few readings and corresponding discussions would need to take place before I would assign this project. First, it would be important to discuss positionality, privilege, and power by asking students to confront their own identities and corresponding privileges (Jones et al., 2016; LSA Inclusive Teaching Initiative, 2017; 
Potapchuk et al., 2012). Next, I would move into discussions of access and ability. Specifically, I would ask students to consider how technological access and ability are directly related to one's cultural capital and existing inequities of race, disability, and gender (Cole, 2019; Hargittai \& Walejko, 2008; Voss, 2018). Finally, I would transition to discussions of what it means to be an anti-racist and an ally that rhetorically listens to and supports historically marginalized groups (Brown, 2020; Lamont, 2016; excerpts from Walton et al., 2019). These readings and discussions would prepare dominantidentified students for the work of more inclusive collaborations before beginning the client project or crafting the team contract.

After these discussions take place, I would reserve two class periods for the team contract process. During the first class period, I would introduce the assignment sheet and then begin the initial steps of team contract preparation before having students get into their groups. I have created a "Team Contract Preparation Handout" (See Figure 1), where I ask students to carefully answer specific questions regarding the client project individually before meeting with their assigned or chosen groups. I specifically ask students to articulate (1) their past experiences in relation to collaborative normalcies; (2) their individual learning goals; (3) potential leadership roles they are interested in; (4) their personal investment levels; (5) their concerns, comfortabilities, and privileges regarding the client project; and (6) how they might better respond to conflict and support other team members. As the instructions state, I would allow students to take this handout home, so they would have time to answer the questions before the next class period. I believe it is valuable for students to articulate these aspects of collaborative work prior to meeting with their team so they have time to consider their 
individual needs, privileges, and potential responses to team conflict. By not knowing who their group members are at this point in the project, students may feel more comfortable in expressing their responses and less pressure to perform for specific team members. 9

During the second class period, I would have students get into their assigned or chosen groups and share their written responses to help students better understand their team members' needs and goals prior to making team decisions. After students share their individual responses, I would then give them the "Client Project Team Contract Handout" to fill out (See Figure 2). As I mention in the instructions, the team contract is preliminary and subject to change as the client project progresses. Teams cannot possibly anticipate every circumstance they might encounter. Rather, the team contract serves as a foundation to return to when difficult circumstances arise. The team contract also serves as a plan of action that makes responsibilities-both individual responsibilities and team responsibilities to each other-apparent.

The team contract handout I have created here includes four main sections: (1) Individual \& Team Goals; (2) Technology \& Communication Plan; (3) Leadership Roles, Individual Tasks, \& Investment Levels; and (4) Team Support \& Conflict Resolution. In the first section, I ask students to separate individual goals from team goals. Often, students are not asked to make this distinction, and individual goals are conflated with team goals. If TPC teacher-scholars don't ask students to articulate both individual and

\footnotetext{
${ }^{9}$ However, this could go both ways. If students are not sure who their team members are, then they may feel the need to perform a certain identity until they know their team members, which could influence their preparatory responses. For the purposes of this thesis, I find revealing teams during the second class period to be more beneficial because this allows students to focus on their individual needs before considering the needs of their team members. The varying effects of group formation-whether assigned, self-selected, or a mixture of both-and when teams should be revealed are important considerations, which I discuss more in the next section.
} 
Figure 1: Team Contract Preparation Handout.

\section{Project III: Team Contract Preparation}

Prior to next class-where you will be meeting with your team to negotiate a team contract-I would like you to carefully answer the following questions individually. These questions are meant to help you articulate what you want to get out of this client project, concerns you have about this client project, and how you personally might make this client project a success for both yourself and your fellow team members. Bring your responses with you next class period to share with your team and craft a personalized team contract.

1. The following questions relate to your past experiences with collaborative work:

a. What kinds of collaborations are encouraged/discouraged in the classroom?

b. What disconnects do you see between classroom collaborations and collaborations that take place outside of the classroom?

c. How might these disconnects be related to normalized expectations of classroom behavior/collaborations?

2. What are your individual goals for this project? In other words, what do you want to learn from this project? Try to craft 2-3 individual learning goals.

3. Based on your individual learning goals, would you be interested in taking on a leadership role within your team? Would leading a specific aspect of the client project help you meet your personal goals? How so?

4. The following questions pertain to your individual investments and commitments:

a. Considering your schedule and outside commitments, how much time can you realistically invest in this client project per week?

b. How might this impact your goals or available roles within the team?

5. The following questions pertain to your concerns, comfortabilities, and privileges:

a. What about this client project worries you? (i.e. concerns about new goals/leadership roles, concerns about technological access/ability, concerns about your investment level or personal time constraints, etc.)

b. What about this client project are you already comfortable with? (i.e. similar deliverables you've created in the past, familiar technologies, leadership roles you've taken on before, etc.)

c. How might these comfortabilities be directly related to your unique positionality and corresponding privileges?

6. The following questions ask you to consider how you personally might respond to constructive criticisms, resolve conflict, and support other team members:

a. How might you better understand and respond to questions and criticisms posed by other team members?

b. How might you help resolve potential conflict if questions or criticisms are misunderstood?

c. How might you support other team members to help them meet their learning goals? 
Figure 2: Client Project Team Contract Handout.

\section{Project III: Team Contract}

This team contract is an agreement between you and your fellow team members that outlines your goals, expectations, and plans for this project. Please fill this out together with each team member's prepared responses in mind. While certain aspects of this team contract may change as your client project progresses, this document serves as a reminder and reference point to return to if confusion, difficulty, or conflict arises.

\section{TEAM MEMBERS}

Team Member 1:

Team Member 2:

Team Member 3:

\section{INDIVIDUAL \& TEAM GOALS}

1. What is/are the primary learning goal(s) for each team member?

Team Member 1:

Team Member 2:

Team Member 3:

2. What learning goals do you have together as a team?

\section{TECHNOLOGY \& COMMUNICATION PLAN}

3. When will your team need to communicate? At what points in the project will open communication be most important? Within what time frame can each team member realistically respond? 
Figure 2, Continued.

4. What technologies will your team use for communication? Do all team members have access to these technologies? If not, are there any alternatives for communication that might be better for your team?

5. What technologies might your team use for your client project and corresponding deliverables? Do all team members have access to these technologies? If not, are there any alternatives for content production that might be better for your team?

\section{LEADERSHIP ROLES, INDIVIDUAL TASKS, \& INVESTMENT LEVELS}

6. Based on individual and team goals, what leadership roles or aspects of the project will each teach member be in charge of?

Team Member 1 will lead:

Team Member 2 will lead:

Team Member 3 will lead:

7. With these leadership roles assigned, what responsibilities or tasks will each team member take on? How much time can each team member realistically invest? (Reminder: Tasks and investment levels may be different for each team member based on their individual goals, needs, and assigned position!) Team Member 1 will complete tasks such as:

Team Member 1 can invest about hours per week. 
Figure 2, Continued.

Team Member 2 will complete tasks such as:

Team Member 2 can invest about hours per week.

Team Member 3 will complete tasks such as:

Team Member 3 can invest about hours per week.

TEAM SUPPORT \& CONFLICT RESOLUTION

8. How will your team support each other to meet both individual and team goals? How will your team track progress toward individual and team goals?

9. What steps will your team take if a team member misses a deadline or turns in work that does not meet the teams' expectations?

10. What steps will your team take if questions, criticisms, or conflict become unproductive? How will you reach a team resolution?

\section{TEAM SIGNATURES}

As a team, we agree to the above goals, expectations, and plans. 
team goals, we risk erasing individual needs within larger group work and defaulting to dominant perspectives.

In the second section, I ask teams to consider when communication will be necessary, realistic response times, and potential technologies for communication and group work. This encourages students to consider issues of access and what technologies might be best for their team. I specifically ask teams to consider technological alternatives because certain technologies might be more accessible than others depending on the given group, and dominant-identified students with access to multiple technologies might not consider alternatives otherwise.

In the third section, I ask teams to assign leadership roles and divide labor. To avoid assigning roles based on White male and non-disabled normalcies, I specifically ask teams to assign leadership roles "based on individual and team goals." This requires teams to consider individual needs when assigning positions. Once leadership roles are decided, I ask teams to articulate individual tasks and investment levels. I include a note that says: "Tasks and investment levels may be different for each team member based on their individual goals, needs, and assigned position!" This note is meant to (1) encourage teams to divide labor based on the leadership position and the individual and (2) counter the normative expectation that each team member must put in an "equal" number of hours. Here, my hope is that students will work toward a more equitable division of labor.

In the final section, I ask teams to consider how they might support each other and what they might do in certain situations. I begin by asking teams how they will support each other and track progress toward both individual and team goals. I specifically use the terminology "support" and "track progress" to encourage positive 
team accountability without assigning a specific method to do so, as teams may prefer different support systems. I then ask teams to outline steps they will take if a team member misses a deadline, turns in unacceptable work, or starts unproductive conflict. I then ask students how they might reach a team resolution. By encouraging students to create a plan with specific steps, conflict may be handled more effectively or avoided altogether. While this team contract is not meant to be an exportable pedagogical tool, I have displayed what a team contract handout might look like in a specific institutional context and the many considerations that must be taken into account to encourage more socially just collaborations.

\section{Limitations and Implications for Future Research}

While my FDC approach to team contracts begins the work of encouraging more socially just collaborations between TPC students, I was not able to fully address factors such as group formation and the assessment of collaborative work. One limitation of this chapter on team contracts is that I have chosen to focus on one specific phase of collaborative work-the moment when teams first come together and begin to interact. With that said, we need more research on other phases of collaborative work as well.

One concern brought up by students in my pilot study and teacher-scholars in the field is the way teams are formed. There is some research on how to form groups manually or algorithmically, ideal group sizes, and the ways that social identities may influence self-selected student groups (England \& Brewer, 2018; Lyn, 2019; Moreno, Ovalle, \& Vicari, 2012). Nine students in my pilot study specifically linked their positive collaborative experiences to small group sizes-with groups of three being a popular choice. However, team contracts do not account for group formation and the power dynamics that might go along with how teacher-scholars assign groups or students self- 
select groups, as this would occur before the team contract is negotiated. More work needs to be done on how an FDC framework might influence student group formation, with research questions such as: (1) In what rhetorical situations is it best to assign groups or let students self-select groups? (2) If I assign groups, what criteria will I use, and how will I ensure those criteria are not based in White male and non-disabled normalcies? (3) If I allow students to self-select groups, how will I prevent group formation based on normative comfort and prevent the isolation of historically marginalized students? (4) Whether or not groups are assigned or self-selected, how will I encourage dominant-identified students to interact differently and better engage without further risking the learning, comfort, and safety of historically marginalized students? Group formation is an important phase of collaborative work that requires further research in combination with social justice frameworks.

Another major phase of classroom collaboration that I did not have the space to fully address in this chapter is the assessment of collaborative work. Scholars such as Inoue (2005 \& 2012), Litterio (2016 \& 2018), and Medina and Walker (2018) all have great work on social justice approaches to contract grading and community-based assessment. I am specifically drawn to the idea of community-based assessment practices used in combination with FDC-informed team contracts. In the last year, I have started to utilize community-based assessment practices to create project rubrics with students. As we create the project rubric together, we rank what we value most and least in the project, we distribute point values based on these rankings, and we decide the kinds of feedback that would be most helpful at different stages in the project. In the future, I would like to conduct more research on the ways community-based assessment 
practices used in conjunction with FDC-informed team contracts might encourage more socially just student collaborations.

Finally, this thesis as a whole calls on TPC teacher-scholars to take up social justice frameworks and conduct more research on the ways we might enact these frameworks to promote equitable and inclusive relationships between students. Prior to any kind of student collaboration, TPC teacher-scholars must consider what projects meet the aims of their courses and the needs of their students. Scaffolding projects and designing assignment sheets is important foundational work, and more research could be done on how social justice frameworks might influence approaches to course and project designs. For example, an FDC framework would ask TPC teacher-scholars to consider questions such as: (1) How will I intervene in rhetoric's violent history and center historically marginalized scholars and students? (2) How will I disrupt White male and non-disabled normalcies in classroom projects and discussions? (3) How will I encourage dominant-identified students to acknowledge their positionality, privilege, and power throughout this course? (4) How will this course reveal oppressive structures and encourage dominant-identified students to take action against these structures? If we plan TPC courses and projects with these kinds of questions in mind, how might this enact change within our classrooms, institutions, and the TPC field in general? Many institutions tout "diversity and inclusion," but we need more research on social justice frameworks and how to implement these frameworks in our course and project designs. Haas and Eble's (2018) collection on key theoretical frameworks in TPC and Walton et al.'s (2019) book on TPC coalition building jump-started this work, but there is still much work to be done to actualize these theoretical frameworks in our classrooms and institutions. 


\section{Conclusion}

I would like to end this thesis by considering two questions: What larger impacts does the cultural-rhetorical study of race, disability, and gender in relation to student collaborations have for the TPC field? And, what can dominant-identified scholars and students do to confront our privileges and work toward more inclusive spaces?

First, I must address this kairotic (and what I'm sure will be historic) moment. I am writing this final chapter in June of 2020-in the midst of the COVID-19 pandemic and the \#BlackLivesMatter and police abolition movements. Here in the U.S., we are seeing nationwide protests against institutional racism and the policing, mass incarceration, and disproportionate killing of Black bodies. If there was ever a time to act, it's now. While we as a country are interrogating the racism inherent in policing, we as TPC teacher-scholars must also be interrogating the racism, ableism, and sexism inherent in the academy and the institutions we work in. As \#BlackInTheIvory has shown us, Black teacher-scholars and students are facing both "discrimination and alienation" on a regular basis, and they are calling on teacher-scholars and "higher education to confront systemic racism within the institution" (Diep, 2020). Now is the time to center historically marginalized teacher-scholars and students in order to actively work toward anti-racist, anti-ableist, and anti-sexist pedagogies. So, how do we begin this work of redressing institutionalized racism, ableism, and sexism? We must start by acknowledging our privileges, examining our fragilities, and confronting our complicity in systems and institutions that have primarily benefitted us. While this is an easy statement to make, what might this look like in our classrooms?

As TPC teacher-scholars, we must acknowledge rhetoric's violent histories and challenge the rhetors and rhetorical practices that have been normalized. As Royster 
(2003) points out, our disciplinary landscape has been dominated by White male viewpoints, and we must turn our focus to "non-normative subjects in non-normative arenas" so that we might intervene in rhetoric's violent histories (p. 157). The problematically White-dominated field of rhetoric studies has chosen to ignore bodies, bodily difference, and rhetorical practices that do not align with normative expectations, and we must turn our attention to those who have been erased. As Chávez (2015) and Wanzer-Serrano (2019) call on us to do, we must shift our theoretical frameworks and engage with rhetoric's multiple histories in different ways. To confront rhetoric's Western and White-centric histories and challenge White male and non-disabled normalcies, we must address the erasure of marginalized bodies and the normalization of dominant cultures' rhetorical practices with students.

Even though these conversations can be difficult and unsettling for some, I believe there are constructive ways to address these violent histories. For example, we might ask students to consider what rhetorical practices they value and why. This can lead to questions such as: What rhetorical practices are deemed "appropriate" in the academy? What rhetorical practices are deemed "inappropriate" in the academy? How are these perceptions based in normative expectations that have been historically harmful? These kinds of discussions make space for students to critically examine how they might be reinscribing White male and non-disabled normalcies in their writing and in their everyday lives. We must also commit to intervening in rhetoric's traditional canon by centering the work of BIPOC rhetors, rhetors with disabilities, female rhetors, and rhetors who are multiply marginalized. Even in contexts of constraint (like myself, as a graduate instructor teaching a first-year composition course with an assigned textbook), we can still exercise agency in different ways to challenge traditional notions 
of rhetoric. As TPC teacher-scholars, we must encourage students to constantly rethink the voices we privilege and how we view rhetoric-what it is, what it does, and what it should do.

Once we address rhetoric's racist, ableist, and sexist histories, we must take an intersectional approach to address positionalities that result in unearned privileges. As Cushman (2005) notes, "Whiteness is the baseline against which all other racial identities are read ... and this reading often uses skin color alone to determine who is, who isn't, and who passes" (p. 390). This argument can be extended to all bodies. All bodies are read. They are raced; they are (dis)abled; they are gendered. We often (if not always) make snap judgments about people and place them into identity categories based on their appearance alone. Cushman (2005) argues that "it's this very taken-forgranted nature of reading a face [or body] that works against creating an understanding of identity that sees it as fluid, changing, historically rooted and influenced by agency" (p. 391). For this reason, we must acknowledge the ways certain positionalities are normalized, which yields unearned privileges. An intersectional approach requires a critical examination of our privileges and how we might use those privileges to benefit those who do not have the same privileges. By acknowledging our own positionality and privileges in the classroom-similar to what I did in chapter one of this thesis-we can show students how to do the same.

One way to do this is by asking students to think about their own identities and how their complex positionalities overlap. The University of Michigan has developed a "Social Identity Wheel," which "prompts students to fill in various social identities (such as race, gender, sex, ability/disability, sexual orientation, etc.) and further categorize those identities based on which matter most in their self-perception and which matter 
most in others' perceptions of them" (LSA Inclusive Teaching Initiative, 2017).

Essentially, once students can acknowledge the various parts of their identities, they can then begin thinking about how their positionalities might align with cultural norms, which would afford them certain privileges. This might lead to classroom conversations about how privilege can be used in both positive and negative ways. Privilege can be wielded in our interactions, in our collaborations, and in our writing, and we must learn and teach students how to use our privilege responsibly. This also means acknowledging our mistakes and modeling genuine apologies. We are human beings just like the students we teach, and we make mistakes just like them. Mistakes are inevitable. Therefore, we must show students an alternative to displays of White fragility by taking responsibility for our actions, apologizing, and moving forward (DiAngelo, 2011). This kind of intersectional approach models that same behavior we expect from students, which encourages them to acknowledge their privileges and use them responsibly.

As we ask students to confront rhetoric's violent histories and their unearned privileges, we must also take an embodied approach that intervenes in normalizing discourses. After teaching a disability-themed course with a focus on rhetorics of normalcy, Selznick (2015) found that rhetoric and composition classrooms could benefit from the study of disability and normalcy because "the issues that disability studies brought to the class such as embodiment, access, social construction, and the material effects of language made my students more conscious of their own language choices and the power that their own rhetoric and compositions would have on social realities and inequities" (p. 10). For this reason, TPC teacher-scholars must intervene in normalizing discourses that reinforce oppressive structures. While Selznick (2015) admits that confronting normalizing discourses in the classroom can be difficult and uncomfortable, 
she argues that it is a necessary step to challenge and dismantle cultural norms and oppressive structures. Language has the power to heal and to harm, and if we do not address this reality with students, we risk reinscribing White male and non-disabled normalcies.

In order to fully intervene in normalizing discourses, we must also intervene in pedagogic violence that erases emotion and affect. When we ask students to confront such violent histories through readings and discussions, emotional and affective responses are inevitable. Anwaruddin (2016) argues that, historically, literacy education has emphasized the reading and writing of texts rather than what texts and literacy practices position us to do next. Therefore, it is important for us-both TPC teacherscholars and students - to consider (1) what texts are trying to make us feel, and in whose interest, and (2) the voices that are centered/silenced in texts. These questions lead us toward a more affective literacy that allows us "to develop emotional relationships with texts that we engage with" (Anwaruddin, 2016, p. 385). Ultimately, Anwaruddin (2016) argues that affective literacies allow us to better grapple with ethical dilemmas and complex emotions to achieve social justice. As TPC teacher-scholars working toward more socially just interactions and collaborations, we must commit to the "reeducation of emotion" and the examination of emotional and affective responses (Worsham, 1998, p. 216). It is important to make space for affective responses and to acknowledge that displays of emotion are perfectly okay-even (and especially) in academic spaces. We must ask students to critically examine their affective responses to course texts and discussions and consider why certain emotional responses may be occurring. This examination of affective responses may lead to the radical empathy that is necessary for socially just and inclusive collaborations. 
So, what do histories of rhetoric, cultural-rhetorical theories, and social justice pedagogies have to do with the study of student collaborations in the TPC classroom? We cannot talk about positive and inclusive collaborations without also addressing rhetoric's violent histories and taking both intersectional and embodied pedagogical approaches that actively work toward anti-racism, anti-ableism, and anti-sexism in the classroom. As Haas and Eble (2018) note, "Using cultural and rhetorical theories to redress social injustices, social justice approaches essentially and ideally couple rhetoric with action to actually make social, institutional, and organizational change toward equity happen" (pp. 4-5). An FDC approach may be one way to do this, but it is important to note that social justice pedagogical approaches are adaptable and always in flux as we continually educate ourselves. As Selznick (2015) writes, "pedagogy is not a static category to be fit into, but rather a philosophy that emerges from our subject positions, identity formations, and our ways of being in the world" (p. 10). This thesis is just a small part of the larger social justice work that must be taken up to confront institutionalized racism, ableism, and sexism and to strive for more inclusive classrooms and collaborations. 


\section{REFERENCES}

Annamma, S. A., Connor, D., \& Ferri, B. (2013). Dis/ability critical race studies (DisCrit): theorizing at the intersections of race and dis/ability. Race Ethnicity and Education, 16(1), 1-31.

Annamma, S. A., Ferri, B. A., \& Connor, D. J. (2018). Disability Critical Race Theory: Exploring the Intersectional Lineage, Emergence, and Potential Futures of DisCrit in Education. Review of Research in Education, 42(1), 46-71.

Anwaruddin, S. M. (2016). Why critical literacy should turn to 'the affective turn': making a case for critical affective literacy. Discourse: Studies in the Cultural Politics of Education, 37(3), 381-396.

Banks, J. (2018). Invisible man: Examining the intersectionality of disability, race, and gender in an urban community. Disability \& Society, 33(6), 894-908.

Bell, C. (2017). Is Disability Studies Actually White Disability Studies? In L. J. Davis (Ed.), The Disability Studies Reader (pp. 406-415). New York, NY: Routledge.

Black Homecoming Committee [@BHC_ISU]. (2019, October 4). A lot of you have been wondering why we've been reluctant to release any details for this year's black homecoming [Tweet]. Twitter.

\section{https://twitter.com/BHC ISU/status/1180203438745014274?s=20}

Blyler, N. R., \& Thralls, C. (1993). The Social Perspective and Professional Communication: Diversity and Directions in Research. In N. R. Blyler \& C. Thralls (Eds.), Professional Communication: The Social Perspective (pp. 3-34). Thousand Oaks, CA: Sage Publications. 
Brown, B. (Host). (2020, June 3). Brené with Ibram X. Kendi on How to Be an Antiracist. [Audio podcast episode]. In Unlocking Us with Brené Brown. Apple Podcasts. https://podcasts.apple.com/us/podcast/brené-with-ibram-x-kendi-onhow-to-be-an-antiracist/id1494350511?i=1000476611079.

Cedillo, C. V. (2018). What Does It Mean to Move?: Race, Disability, and Critical Embodiment Pedagogy. Composition Forum, 39(1), 1-21.

Chávez, K. R. (2015). Beyond Inclusion: Rethinking Rhetoric's Historical Narrative. Quarterly Journal of Speech, 101(1), 162-172.

Cole, N. L. (2019). What Is Cultural Capital? Do I Have It?: An Overview of the Concept. ThoughtCo. Retrieved March 29, 2020, from https://www.thoughtco.com/what-is-cultural-capital-do-i-have-it-3026374.

Collins, P. H., \& Bilge, S. (2016). Intersectionality. Malden, MA: Polity Press.

Crenshaw, K. (1991). Mapping the Margins: Intersectionality, Identity Politics, and Violence against Women of Color. Stanford Law Review, 43(6), 1241-1299.

Cox, M. (2019). Shifting Grounds as the New Status Quo: Examining Queer Theoretical Approaches to Diversity and Taxonomy in the Technical Communication Classroom. In A. M. Haas \& M. F. Eble (Eds.), Key Theoretical Frameworks: Teaching Technical Communication in the Twenty-First Century (pp. 287-303). Logan, UT: Utah State University Press.

Cushman, E. (2005). Face, Skins, and the Identity Politics of Rereading Race. Rhetoric Review, 24(4), 389-395.

Danielewicz, J., \& Elbow, P. (2009). A Unilateral Grading Contract To Improve Learning and Teaching. College Composition and Communication, 61(2), 244-268. 
DiAngelo, R. (2011). White Fragility. International Journal of Critical Pedagogy, 3(3), 54-70.

Diep, F. (2020). 'I Was Fed Up': How \# BlackInTheIvory Got Started, and What Its Founders Want to See Next. The Chronicle of Higher Education. https://www.chronicle.com/article/I-Was-Fed-Up-How/248955/.

Dolmage, J. (2009). Metis, Mêtis, Mestiza, Medusa: Rhetorical Bodies across Rhetorical Traditions. Rhetoric Review, 28(1), 1-28.

Dolmage, J., \& Lewiecki-Wilson, C. (2010). Refiguring Rhetorica: Linking Feminist Rhetoric and Disability Studies. In E. E. Schell \& K. J. Rawson (Eds.), Rhetorica in Motion: Feminist Rhetorical Methods \& Methodologies (pp. 23-38).

Pittsburgh, PA: University of Pittsburgh Press.

Edwards, J. (2018). Race and the Workplace: Toward a Critically Conscious Pedagogy. In A. M. Haas \& M. F. Eble (Eds.), Key Theoretical Frameworks: Teaching Technical Communication in the Twenty-First Century (pp. 268-286). Logan, UT: Utah State University Press.

England, P. S., \& Brewer, P. E. (2018). What Do Instructors Need to Know about Teaching Collaboration? In T. Bridgeford (Ed.), Teaching Professional and Technical Communication: A Practicum in a Book (pp. 159-175). Logan, UT: Utah State University Press.

Garland-Thomson, R. (2011). Integrating Disability, Transforming Feminist Theory. In K. Q. Hall (Ed.), Feminist Disability Studies (pp. 13-47). Bloomington, IN: Indiana University Press. 
Haas, A. M. (2012). Race, Rhetoric, and Technology: A Case Study of Decolonial Technical Communication Theory, Methodology, and Pedagogy. Journal of Business and Technical Communication, 26(3), 277-310.

Haas, A. M., \& Eble, M. F. (Eds). (2018). Key Theoretical Frameworks: Teaching Technical Communication in the Twenty-First Century. Utah State University Press.

Hall, K. Q. (2011). Reimagining Disability and Gender through Feminist Studies: An Introduction. In K. Q. Hall (Ed.), Feminist Disability Studies (pp. 1-10). Bloomington, IN: Indiana University Press.

Hargittai, E. \& Walejko, G. (2008). The Participation Divide: Content Creation and Sharing in the Digital Age. Information, Communication \& Society, 11(2), 239-256.

Inoue, A. B. (2005). Community-based assessment pedagogy. Assessing Writing, 9(1), 208-238.

Inoue, A. B. (2012). Racial Methodologies for Composition Studies: Reflecting on Theories of Race in Writing Assessment Research. In L. Nickoson \& M. P. Sheridan (Eds.), Writing Studies Research in Practice: Methods and Methodologies (pp. 125-139). Carbondale, IL: Southern Illinois University Press.

Jones, N. N., Moore, K. R., \& Walton, R. (2016). Disrupting the Past to Disrupt the Future: An Antenarrative of Technical Communication. Technical Communication Quarterly, 1-19.

Lamont, A. (2016). Guide to Allyship. Amélie Stuido. https://guidetoallyship.com. Litterio, L. M. (2016). Contract Grading in a Technical Writing Classroom: A Case Study. The Journal of Writing Assessment, 9(2), 1-8. 
Litterio, L. M. (2018). Contract grading in the technical writing classroom: Blending community-based assessment and self-assessment. Assessing Writing, 38(1), 1-9.

LSA Inclusive Teaching Initiative. (2017). Social Identity Wheel. University of Michigan, https://sites.lsa.umich.edu/inclusive-teaching/2017/08/16/socialidentity-wheel/.

Lyn, O. S. (2019). The Influence of Social Categories on Students' Self-Selected Group Work Formation in a Private University in Malaysia. e-Bangi Journal of Social Sciences and Humanities, 16(1), 1-12.

Medina, C., \& Walker, K. (2018). Validating the Consequences of a Social Justice Pedagogy: Explicit Values in Course-Based Grading Contracts. In A. M. Haas \& M. F. Eble (Eds.), Key Theoretical Frameworks: Teaching Technical Communication in the Twenty-First Century (pp. 46-67). Logan, UT: Utah State University Press.

Miller, C. R. (1979). A Humanistic Rationale for Technical Writing. College English, $40(6), 610-617$

Moeller, M. E. (2018). Advocacy Engagement, Medical Rhetoric, and Expediency: Teaching Technical Communication in the Age of Altruism. In A. M. Haas \& M. F. Eble (Eds.), Key Theoretical Frameworks: Teaching Technical Communication in the Twenty-First Century (pp. 212-238). Logan, UT: Utah State University Press.

Moreno, J., Ovalle, D. A., \& Vicari, R. M. (2012). A genetic algorithm approach for group formation in collaborative learning considering multiple student characteristics. Computers \& Education, 58(1), 560-569. 
Porter, J. E., Sullivan, P., Blythe, S., Grabill, J. T., \& Miles, L. (2000). Institutional Critique: A Rhetorical Methodology for Change. College Composition and Communication, 51(4), 610-642.

Potapchuk, M., \& MP Associates (2012). White Culture. [Worksheet]. World Trust Educational Services.

\section{https://www.racialequitytools.org/resourcefiles/whtieculturehandout.pdf.}

Price, M. (2009). "Her Pronouns Wax and Wane”: Psychosocial Disability, Autobiography, and Counter-Diagnosis. Journal of Literary \& Cultural Disability Studies, 3(1), 11-33.

Rainey, K. T., Turner, R. K., \& Dayton, D. (2005). Do Curricula Correspond to Managerial Expectations?: Core Competencies for Technical Communicators. Technical Communication, 52(3), 323-352.

Royster, J. J. (2003). Disciplinary Landscaping, or Contemporary Challenges in the History of Rhetoric. Philosophy \& Rhetoric, 36(2), 148-167.

Rude, C. D. (2009). Mapping the Research Questions in Technical Communication. Journal of Business and Technical Communication, 23(2), 174-215.

Selznick, H. (2015). Investigating Students' Reception and Production of Normalizing Discourses in a Disability-Themed Advanced Composition Course. Disability Studies Quarterly, 35(2), 1-18.

Smyser-Fauble, B. (2018). The University Required Accommodations Statement: What “Accommodation” Teaches Technical Communication Students and Educators. In A. M. Haas \& M. F. Eble (Eds.), Key Theoretical Frameworks: Teaching Technical Communication in the Twenty-First Century (pp. 68-90). Logan, UT: Utah State University Press. 
Spidell, C., \& Thelin, W. H. (2006). Not Ready to Let Go: A Study of Resistance to Grading Contracts. Composition Studies, 31(1), 35-68.

Voss, J. (2018). Who Learns from Collaborative Digital Projects? Cultivating Critical Consciousness and Metacognition to Democratize Digital Literacy and Learning. Composition Studies, 46(1), 57-80.

Walton, R., Moore, K. R., \& Jones, N. N. (2019). Technical Communication After the Social Justice Turn: Building Coalitions for Action. New York, NY: Routledge.

Wanzer-Serrano, D. (2019). Rhetoric's rac(e/ist) problems. Quarterly Journal of Speech, 105(4), 465-476.

Weiss, G. (2015). The normal, the natural, and the normative: A Merleau-Pontian legacy to feminist theory, critical race theory, and disability studies. Continental Philosophy Review, 48(1), 77-93.

Wolfe, J. (2010). Team Writing: A Guide to Working in Groups. Boston, MA: Bedford/St. Martin's.

Worsham, L. (1998). Going Postal: Pedagogic Violence and the Schooling of Emotion. $J A C, 18(2), 213-245$. 


\section{APPENDIX A: SURVEY QUESTIONS}

1. Please provide the following demographic information. These are short answer questions so that you can self-identify as you normally would. If you are not comfortable sharing any of the following demographic information, then you may leave that field blank.

Note: Do not include any information that could personally identify you.
a. Declared Major
b. Age
c. Gender
d. Race/Ethnicity
e. Disability (Write N/A if not applicable)

2. What experiences have you had with collaboration in the classroom? In other words, what experiences have you had with group work in a classroom setting? Please select all that apply.
a. Small-group discussions
b. Think-pair-share (e.g. think individually, pair up in groups, share with class)
c. Reciprocal teaching (e.g. group teaching, leading group discussions, etc.)
d. Group assignments (e.g. small, informal group assignments)
e. Group projects (e.g. large, high-stakes group projects)
f. Other

3. What has been your overall experience with group work in a classroom setting? Is there a specific instance that comes to mind? If so, please share your story! 
4. How would you assess your overall experience with group work in a classroom setting?
a. Positive
b. Negative
c. Neutral

5. Have you ever participated in collaborative writing (or group writing) in a classroom setting? (e.g. Have you ever produced a written document with one or more team members?)
a. Yes
b. No
c. I'm not sure

6. What has been your overall experience with collaborative writing (or group writing) in a classroom setting? Is there a specific instance that comes to mind? If so, please share your story!

7. How would you assess your overall experience with collaborative writing (or group writing) in a classroom setting?
a. Positive
b. Negative
c. Neutral 


\section{APPENDIX B: PARTICIPANT DEMOGRAPHICS}

Chart 1: Participants by Major.

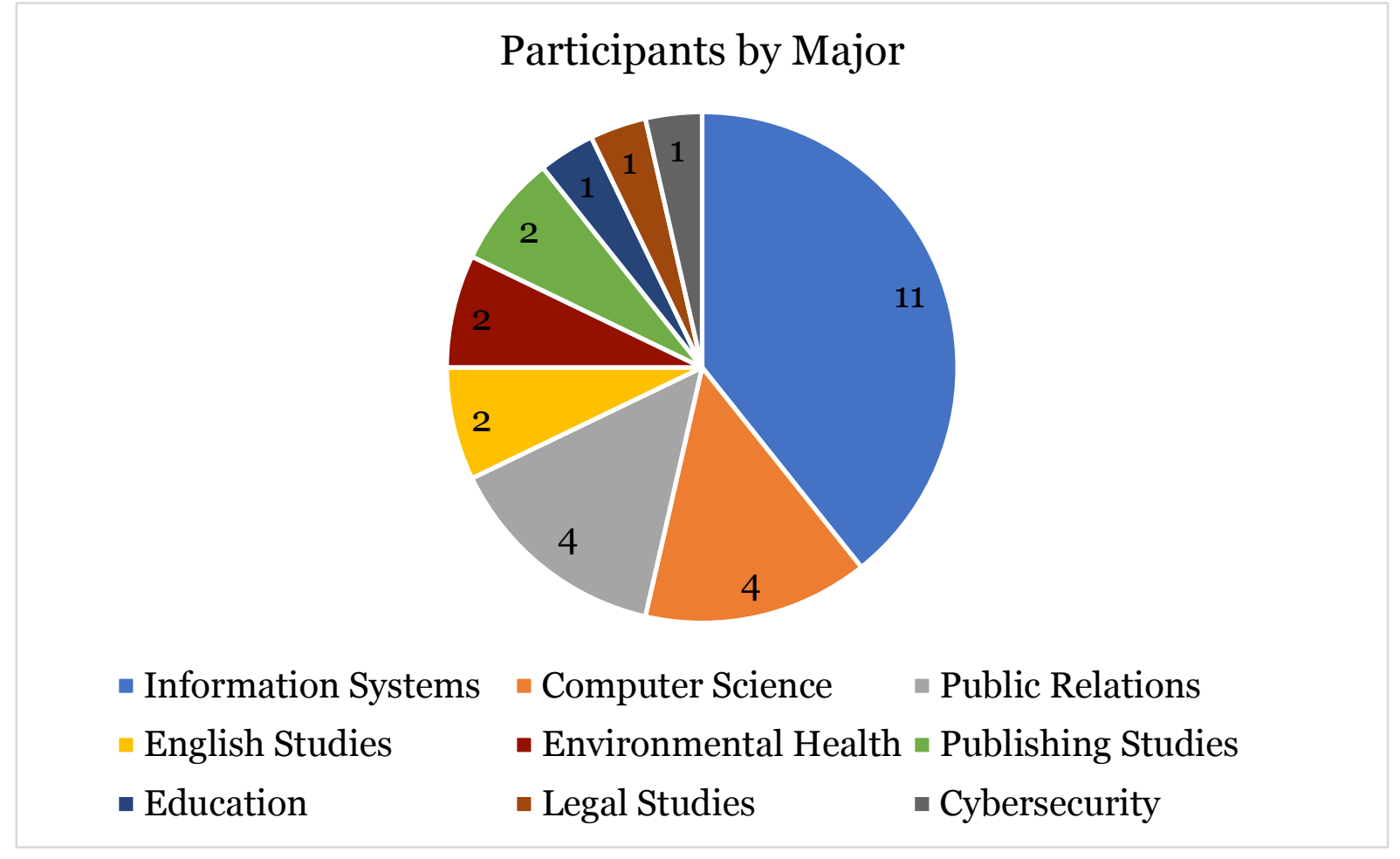

Chart 2: Participants by Gender.

Participants by Gender

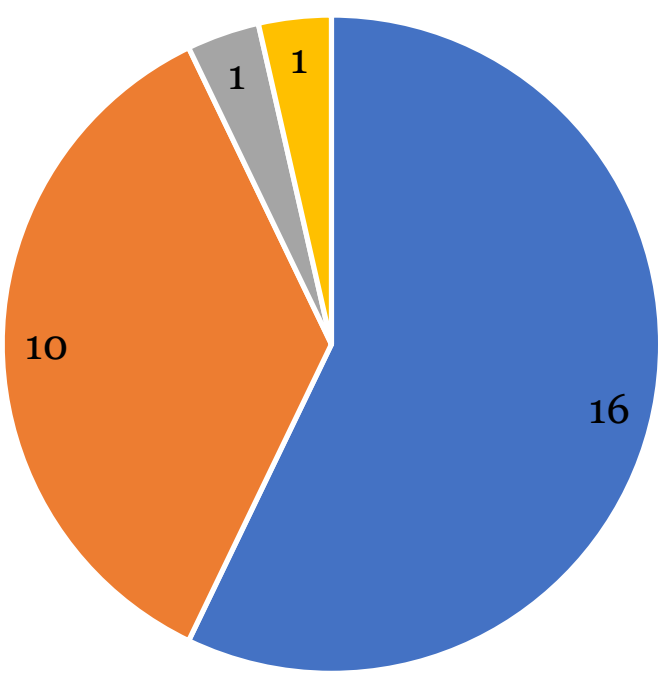

- Female $\quad$ Male $\quad$ Non-Binary $\backsim$ Did not disclose 
Chart 3: Participants by Race/Ethnicity.

\section{Participants by Race/Ethnicity}

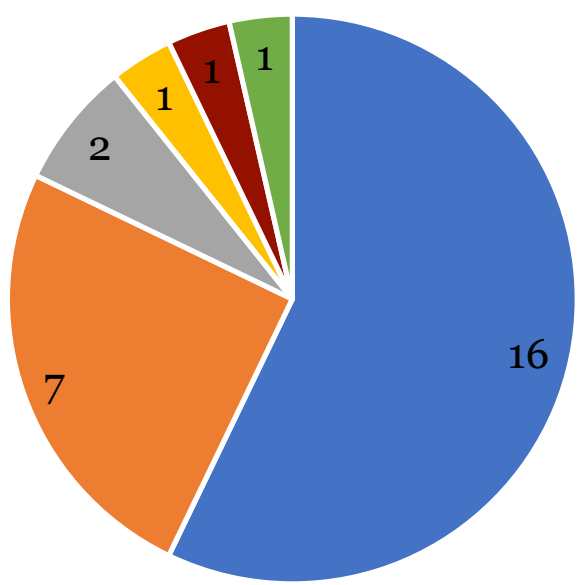

- White

- Asian

- Black/African

- Hispanic/Latinx - Biracial

- Did not disclose

Chart 4: Participants by Disability.

Participants by Disability

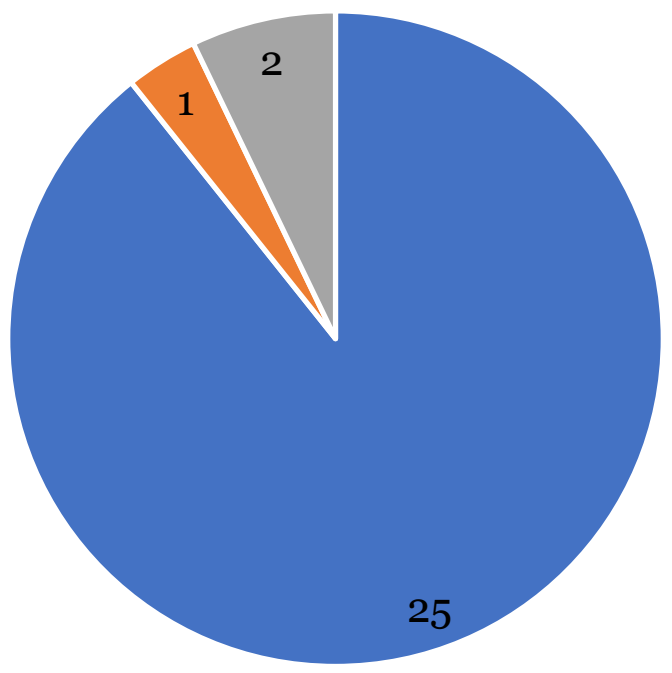

- Non-Disabled $\quad$ ADHD $\square$ Did not disclose 


\begin{abstract}
Project III: Client Project ${ }^{1}$ (30\%)
Working in groups of three, you and your team members will identify a client for whom you will produce a technical deliverable. Your team will establish a client-consultant relationship with a local university group, non-profit, or small business entity in order to research, propose, and produce an appropriate deliverable for the client organization. Think of the various local organizations you are already familiar or involved with: campus student groups, community organizations/non-profits, small businesses (not corporate), etc. I am open to other ideas as well. The goals of this project include establishing client rapport, conducting organizational research about your client, conducting genre research about the deliverable that you will produce, honing rhetorical approaches to project development, and successfully collaborating with colleagues.
\end{abstract}

\title{
DELIVERABLES
}

This client project will consist of the following components:

- Team contract. Your team contract should outline individual/team goals, equitably divide the workload, and establish team member expectations regarding communication and conflict.

- Informal proposal memo written to your instructor. Your team is to create a proposal memo in which you propose a client for the project, a rationale for the proposed client, a potential deliverable for the project, and your production considerations. (I reserve the right to ask your team to find a new organization or consider other deliverables.)

- Interview \& organizational/genre research notes. Document each step of your research process, including your interview, your organizational research, and your genre research. As a team, you may decide the way in which you document and organize your research notes.

- Formal proposal memo written to your client. Your team is to create a formal proposal memo in which you articulate your vision for the deliverable and its production. Your proposal should specify the deliverable's rhetorical purpose, audience, design, production, and possible production costs.

- Deliverable drafts for your instructor and for your client. After gaining client approval, your team is to draft the proposed deliverable for peer review and for client feedback.

- Final deliverables for your instructor and for your client. After receiving peer and client feedback, your team is to deliver a final version, including a printed hard copy and an editable electronic version for future updates.

- Record of correspondence between you and your client.

- Project portfolio including all of the above documents. Finally, your team is to create a project portfolio, which is a collection of your client project materials. The portfolio is to provide your instructor with a researcher's view of your entire project. If in doubt, keep the document.

\section{ASSESSMENT}

This project will be graded holistically (meaning an overall grade will be assigned to your team's client project rather than grading each individual component) with the following questions in mind:

- How successfully does the deliverable meet the client's need? Does the deliverable clearly respond to the client's need as outlined in the informal and formal proposals?

- Does the deliverable take into account the team's organizational/genre research?

- Is the content provided in the deliverable appropriate for its intended audience/users?

- How well is the deliverable designed, organized, and formatted?

- How successfully do team members communicate and collaborate? (Assessment of collaboration will be based upon your official team contract along with your formal reflection emails and your team member evaluation forms, which will be completed after the client project is finalized.)

${ }^{1}$ I would like to acknowledge that this assignment sheet draws upon the previous labor of Dr. Angela Haas, Dr. Elise Verzosa Hurley, and Lisa Dooley. I appreciate the work that each has done to make this possible! 